\title{
Genetic Landscape of Nonobstructive Azoospermia and New Perspectives for the Clinic
}

\author{
Miriam Cerván-Martín ${ }^{1,2}$, José A. Castilla ${ }^{2,3,4}$, Rogelio J. Palomino-Morales ${ }^{2,5}$ and \\ F. David Carmona $1,2, *$ (D)
}

1 Departamento de Genética e Instituto de Biotecnología, Universidad de Granada, Centro de Investigación Biomédica (CIBM), Parque Tecnológico Ciencias de la Salud, Av. del Conocimiento, s/n, 18016 Granada, Spain; mcervan@ugr.es

2 Instituto de Investigación Biosanitaria ibs.GRANADA, Av. de Madrid, 15, Pabellón de Consultas Externas 2, $2^{a}$ Planta, 18012 Granada, Spain; josea.castilla.sspa@juntadeandalucia.es (J.A.C.); rpm@ugr.es (R.J.P.-M.)

3 Unidad de Reproducción, UGC Obstetricia y Ginecología, HU Virgen de las Nieves, Av. de las Fuerzas Armadas 2, 18014 Granada, Spain

4 CEIFER Biobanco-NextClinics, Calle Maestro Bretón 1, 18004 Granada, Spain

5 Departamento de Bioquímica y Biología Molecular I, Universidad de Granada, Facultad de Ciencias, Av. de Fuente Nueva s/n, 18071 Granada, Spain

* Correspondence: dcarmona@ugr.es; Tel.: +34-958-241-000 (ext 20170)

Received: 29 December 2019; Accepted: 16 January 2020; Published: 21 January 2020

\begin{abstract}
Nonobstructive azoospermia (NOA) represents the most severe expression of male infertility, involving around $1 \%$ of the male population and $10 \%$ of infertile men. This condition is characterised by the inability of the testis to produce sperm cells, and it is considered to have an important genetic component. During the last two decades, different genetic anomalies, including microdeletions of the $\mathrm{Y}$ chromosome, karyotype defects, and missense mutations in genes involved in the reproductive function, have been described as the primary cause of NOA in many infertile men. However, these alterations only explain around $25 \%$ of azoospermic cases, with the remaining patients showing an idiopathic origin. Recent studies clearly suggest that the so-called idiopathic NOA has a complex aetiology with a polygenic inheritance, which may alter the spermatogenic process. Although we are far from a complete understanding of the molecular mechanisms underlying NOA, the use of the new technologies for genetic analysis has enabled a considerable increase in knowledge during the last years. In this review, we will provide a comprehensive and updated overview of the genetic basis of NOA, with a special focus on the possible application of the recent insights in clinical practice.
\end{abstract}

Keywords: male infertility; azoospermia; genetic component; mutations; SNPs

\section{Introduction}

Infertility is becoming a growing global public health issue according to the World Health Organization (WHO, Geneva, Switzerland), which is warning about the relevant impact that this condition has on society and the economy. Despite the difficulty in estimating the prevalence of male and female contributions to infertility, it has been reported that about 50 million couples worldwide may be affected, with male infertility contributing to half of those cases approximately [1,2]. Nonobstructive azoospermia (NOA) is considered the clinically most severe expression of male infertility, affecting around $1 \%$ of the male population and $10 \%$ of infertile men [3-7]. This condition is defined by a complete lack of sperm cells in the ejaculate without any reproductive tract obstruction, likely related to a failure in the spermatogenic process [8]. However, such a phenotype has extremely diverse causes (influencing different processes like gonad differentiation, the hypothalamic-pituitary axis function, and spermatogenesis), making this a highly heterogeneous disease [9]. Single genetic anomalies 
(including chromosome aberrations and point mutations) can explain around $25 \%$ of NOA patients, with the remaining patients being classified as idiopathic [10]. In this regard, cumulating knowledge clearly suggests that idiopathic NOA has a multifactorial aetiology, in which both environmental and genetic factors may contribute to disease development. In these cases, the genetic predisposition is likely conferred by common variations of the human genome, mostly single-nucleotide polymorphisms (SNPs) and copy number variants (CNVs), which complicate the elucidation of the underlying pathological mechanisms [9]. Identifying the genetic risk factors of NOA would definitively help urologists to improve both care and counselling of affected men.

This review aims to summarise the current knowledge on the genetic background of NOA, with emphasis on the potential impact that the recent insights could have in the management of affected individuals who hope to father a biological child.

\section{The Spermatogenic Process}

The testis represents a crucial organ for male individuals, since it is responsible for androgen production and generation of sperm cells that will carry the genetic inheritance to the offspring. This organ develops from a gonadal primordium that has the potential to differentiate either as testis or ovary. As a consequence, the molecular network underlying gonad development and function is extremely complex, and subtle alterations may produce very relevant clinical phenotypes [11].

After puberty, hundreds of millions of male gametes are generated daily within the wall of the seminiferous tubules in a process known as spermatogenesis [12]. This process implies a series of events in a stepwise fashion, including several division rounds of diploid spermatogonial stem cells (SSCs), meiosis of spermatocytes, and morphological differentiation of spermatids (Figure 1). Once all these steps are completed, mature spermatozoa are released into the lumen of the tubule so they can be stored in the epididymis until ejaculation. In humans, the whole process is estimated to take around three months, and it requires a delicate physical and molecular interaction between germ cells and Sertoli cells, which are the somatic supporting cells of the tubule. Other somatic cells outside the tubule, such as Leydig and peritubular-myoid cells, are also important for this cross-talk $[13,14]$.

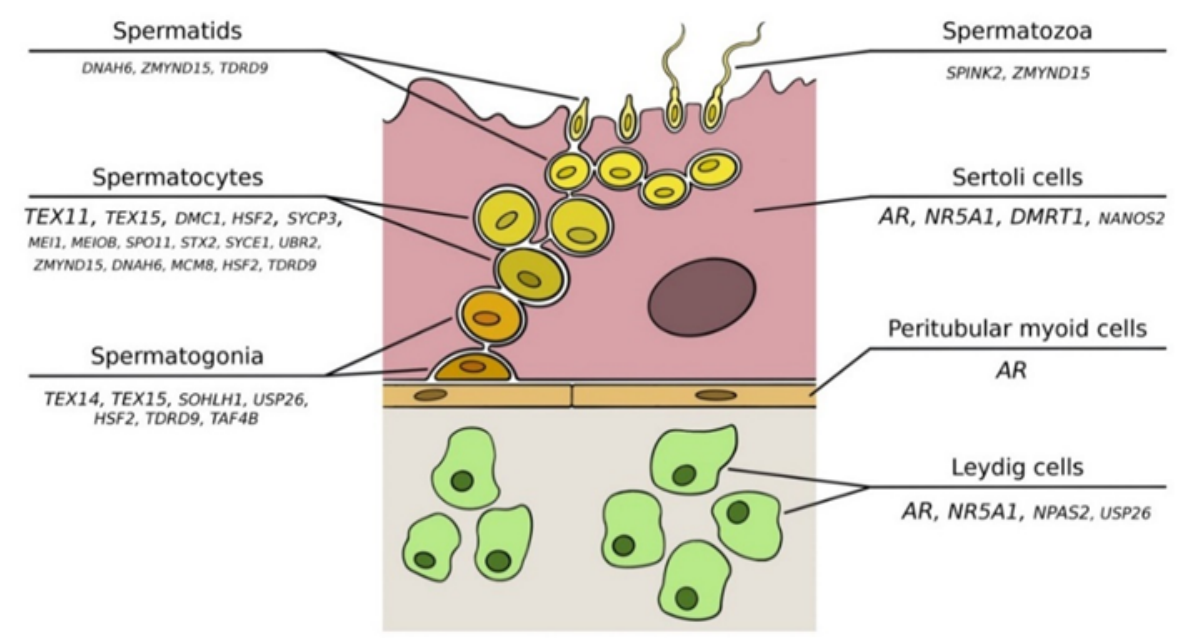

Figure 1. Schematic illustration of spermatogenesis. Genes with reported mutations associated with nonobstructive azoospermia are shown in the cells in which they are expressed. The font size correlates with the strength of the evidence.

Different populations of spermatogonia have been described, all of them residing in the innermost part of the tubule wall. Molecular markers common to all SSCs (e.g., FOXO1, CDH1, ZBTB16, SALL4, and LIN28) as well as SSC type-specific markers (e.g., ID4, PAX7, BMI1, GFRa1, and NANOS2) have been reported [15]. Once the differentiation program has been initiated, a self-renewing SSC divides asymmetrically to maintain the undifferentiated pool and to generate a new spermatogenic lineage 
(A-aligned spermatogonia). At this step, a genetic commitment to complete the spermatogenic process has been initiated, leading to differentiation to A1 spermatogonia, which are characterised by the expression of the cKIT receptor. Subsequently, A1 spermatogonia undergo several mitotic divisions generating A2, A3, A4, intermediate and B spermatogonia, and primary spermatocytes that will initiate meiosis to produce haploid secondary spermatocytes. Finally, biologically functional male gametes will be produced by morphological maturation of secondary spermatocytes, which will differentiate into spermatids and spermatozoa in a process known as spermiogenesis [16].

Because of the high relevance and complexity of the spermatogenesis process, a large number of molecules are involved in its regulatory mechanisms, such as the GnRH/FSHLH, GDNF/RET/GFRA1, FGF2/MAP2K1, CXCL12/CXCR4, retinoic acid, androgen and oestrogen signalling pathways [16-18]. Indeed, it has been estimated that more than 2000 genes may be involved in the maintenance of the germ cell population and satisfactory accomplishment of meiosis [19]. Besides, epigenetics and DNA integrity have been also shown to play relevant roles in this process $[20,21]$. Therefore, alterations of such mechanisms may result in the development of infertility issues [10].

\section{Monogenic Causes of Nonobstructive Azoospermia}

Around $10 \%$ of male infertility diagnoses are due to azoospermia [22]. Known causes of azoospermia include endocrine and chronic diseases that affect the hypothalamic-pituitary-gonadal axis (e.g., hypogonadism or diabetes), but also pathologic conditions that disrupt the transport of sperm through the vas deferens (e.g., maldescended testes, varicocele, malignancy, or urogenital infections) [23]. However, in one-third of azoospermia patients there is a discernible genetic anomaly responsible for spermatogenic failure [6]. In this regard, genetic diagnostic testing for azoospermia is usually based on the detection of karyotype aberrations, $\mathrm{Y}$ chromosome microdeletions, and cystic fibrosis transmembrane conductance regulator (CFTR) mutations [24].

\subsection{Karyotype Abnormalities}

It is widely known that the presence of cytogenetic defects may interfere with the spermatogenic process. In this regard, the aneuploidy rate in NOA patients is ten times higher than that observed in men with obstructive azoospermia [25]. Indeed, sex chromosome aneuploidies represent the most common cause of NOA, especially Klinefelter syndrome (47, XXY) [26-28]. This syndrome affects approximately $0.15 \%$ of men, which show testicular atrophy and dysfunction as a consequence of hyalinization of the seminiferous tubules at mid-puberty, with loss of germ cells and hyperplasia of Leydig cells [29]. However, although more than $95 \%$ of Klinefelter patients have an NOA diagnosis, focal spermatogenesis has been observed in cases of mosaicism 47, XXY/46, XY in the germ line, allowing these individuals to father a child by testicular sperm extraction (TESE) techniques [30].

Other structural chromosome mutations have been also associated with NOA, including sex and autosomal chromosome rearrangements, and translocations between $\mathrm{X}$ and $\mathrm{Y}$ chromosomes or between sex chromosomes and autosomes, which may involve crucial genes for spermatogenesis [28].

\subsection{Y Chromosome Microdeletions}

The key role in spermatogenesis of a genomic region within the long arm of the $\mathrm{Y}$ chromosome (Yq) has been known for more than four decades [31]. Different studies reported that several terminal and interstitial microdeletions of Yq were associated with NOA, identifying three distinct intervals essential for male fertility that were called azoospermia factor (AZF) a, b, and c (located in proximal, middle, and distal Yq11 subregions, respectively) [32,33]. Subsequently, with the use of more advanced sequencing methods, different breakpoint hotspots involving five major palindromes (labelled P1 through P5) were identified [34]. However, in clinical practice, the AZF nomenclature is still used to define the different deletion patterns, i.e., AZFa, AZFb (P5/proximal P1), AZFbc (P5/distal P1 or P4/distal P1), and AZFc (b2/b4) [35]. 
The $\mathrm{Yq}$ microdeletions are a consequence of intrachromosomal non-allelic homologous recombination events (due to the highly repetitive structure of the $Y$ chromosome) [36-39], and overall they are present in 5\%-10\% of azoospermic patients [40]. The deleterious effect on male fertility is caused by the loss of several key regulatory genes of spermatogenesis [35]. Some of them are described below.

\subsubsection{USP9Y}

USP9Y (ubiquitin-specific protease 9, Y chromosome, MIM*400005), also known as DFFRY or SPGFY2, represents one of the major AZFa genes. It encodes a member of the peptidase C19 family that confers stability and protection to ubiquitin-conjugated proteins involved in germ cell survival, through their deubiquitination [41,42]. Its expression is restricted to spermatids, and point mutations in this gene can lead to different clinical phenotypes of male infertility related to reduced mobility and concentration of sperm cells, including spermatid maturation arrest, oligospermia, or asthenozoospermia [43-47]. Similarly, complete loss of the gene has been associated with NOA [48,49].

\subsubsection{DDX3Y}

The protein encoded by DDX3Y (DEAD/H box 3, Y-linked, MIM*400010), another AZFa gene formerly known as $D B Y$, belongs to a family of ATP-dependent helicases involved in the regulation of the cell cycle through intramolecular interactions during RNA transcription, translation, and intron splicing [50]. A testis-specific expression of some DDX3Y isoforms has been reported, particularly in the male germ line [51,52]. Interestingly, there is a homologue DDX3Y in the X chromosome (DDX3X) that shares around $95 \%$ of the DNA sequence and seems to have similar molecular functions. However, $D D X 3 X$ is mostly expressed during spermatid maturation and DDX3Y in early meiosis [53,54]. Although there is no direct evidence yet, it is likely that depletion of DDX3Y results in Sertoli cell-only syndrome (SCO) [35].

\subsubsection{EIF1AY}

One of the genes located within the AZFb region is EIF1AY (eukaryotic translation initiation factor 1a, Y-linked, MIM*400014) [55]. Its encoded protein plays an important role in start codon recognition by the translation initiation machinery during spermatogenesis [56]. It has been suggested that the absence of EIF1AY expression may contribute to NOA development [57].

\subsubsection{RPS4Y2}

RPS4 refers to a highly conserved protein family involved in mRNA binding to the ribosome [58]. In nonhuman primates, two RPS4 genes have been described, named RPS4X and RPS4Y (located in chromosome $\mathrm{X}$ and $\mathrm{Y}$, respectively). Interestingly, the human RPS4Y has two functional Y-linked paralogs, named RPS4Y1 (ribosomal protein s4, Y-linked, 1, MIM*470000) and RPS4Y2 (ribosomal protein s4, Y-linked, 2, MIM*400030), which makes this a unique feature compared to other ribosomal proteins [59,60]. In contrast with its X-linked homologue, RPS4Y2 has a testis-specific expression pattern, being proposed as a key player in the post-transcriptional regulation during germ cell development $[59,61]$. The fact that RPS4Y2 maps within the AZFb region makes this gene a good candidate to explain the development of male infertility traits when this genomic region is depleted [35].

\subsubsection{KDM5D}

Another relevant AZFb gene is KDM5D (lysine-specific demethylase $5 \mathrm{~d}, \mathrm{MIM}^{*} 426000$ ), also known as JARID1D. It encodes a conserved protein of the family of histone demethylases, which have crucial roles in the epigenetic regulation of gene expression. KDM5 proteins catalyse the removal of methyl groups from histone $\mathrm{H} 3$ lysine 4 methylation marks (H3K4me) in the genome, acting as transcriptional repressors $[62,63]$. It has been observed that KDM5D-mediated H3K4 demethylation is required for 
sexually dimorphic gene expression, and defects in the regulatory mechanism of this enzyme have been associated with different tumorigenic processes $[64,65]$. Regarding spermatogenesis, it seems that KDM5D is directly involved in chromatin remodelling and condensation during meiosis, acting in a cooperative manner with the MSH5 DNA repair factor $[66,67]$.

\subsubsection{DAZ}

Because of the evolutionary history of the sex chromosomes, the $\mathrm{Y}$ chromosome contains several ampliconic regions (male specific-sequences of the $\mathrm{Y}$ chromosome enriched with large segmental duplications that involve frequently complex structural arrangements), most of them located in the AZFc region, which have been evolved from $\mathrm{X}$ chromosome or even autosome counterparts [68]. The amplicons are arranged as direct repeats, inverted repeats, or palindromes, giving rise to multiple copies of the so-called "ampliconic genes", which are prone to undergo processes of intra-chromosomal recombination events, in a process known as "gene conversion". Interestingly, these multicopy genes show variations in their sequence, structure, and copy number amongst individuals [69]. As a consequence of this large sequence identity, deletions involving the AZFc region represent the most common Yq microdeletions (more than $80 \%$ ) and have been directly involved with NOA development $[39,70]$. One of these multicopy gene families is $D A Z$ (deleted in azoospermia, MIM*400003), which evolved from the autosomal gene DAZL (deleted in azoospermia-like, MIM*601486) [71]. DAZ has four copies distributed into two different clusters (DAZ1/2 and DAZ3/4), and their expression is restricted to the testis [72]. It encodes an RNA-binding protein involved in RNA translation during sexual differentiation of $X Y$ germ cells, acting as antagonist of NANOS, another essential protein required for meiosis initiation [73]. Conditional inactivation of Dazl in the gonads of mouse models leads to complete absence of gamete production, highlighting the essential role of these proteins in gametogenesis [74].

Other multicopy gene families (involving ampliconic regions of the $\mathrm{Y}$ chromosome) potentially related to spermatogenesis and, therefore, are a candidate for NOA development include TSPY (testis-specific protein, Y-linked, MIM*480100, with 35 copies), VCY (variably charged, Y chromosome, MIM*400012, with 2 copies), XKRY (XK-related protein on Y chromosome, MIM*400015, with 2 copies), CDY (chromodomain protein, Y chromosome, MIM*400016, with 4 copies), HSFY1 (heat-shock transcription factor, Y-linked, MIM*400029, with 2 copies), RBMY (RNA-binding motif protein, $\mathrm{Y}$ chromosome, MIM*400006, with 6 copies), PRY (PTPBL-related gene on Y, MIM*400019, with 2 copies), and BPY2 (basic protein, Y chromosome, 2, MIM*400013, with 3 copies) [35].

\subsection{Autosomal Monogenic Factors}

The widespread application of novel technologies for genetic investigation of human disorders, such as next-generation sequencing (NGS), has allowed the identification of a large number of mutations in putative male infertility genes [75]. However, because of the lack of validation studies in most cases (and the considerably lower incidence of known monogenic alterations in male infertility compared to chromosomal abnormalities), the routine for genetic diagnostic testing has remained unaltered during the last two decades. Current genetic tests are based on karyotyping, analysis of the AZF region, and the screening of gene mutations associated with congenital hypogonadotropic hypogonadism $(\mathrm{CHH}$, a very rare condition characterised by gonadotropin deficiency and low levels of sex steroid hormones) and obstructive azoospermia, being effective only in around $20 \%$ of azoospermic men [76]. Some of the described NOA genes with a potential value as diagnostic markers for NOA are summarised in this section.

\subsubsection{AR}

AR (androgen receptor, MIM*313700), also known as DHTR (dihydrotestosterone receptor), represents the only gene that is currently considered for genetic testing and counselling in the diagnosis of NOA [10]. $A R$ is an X-linked gene that encodes a transcription factor of the steroid-hormone 
activated receptor family, which regulates the expression of androgen-responsive genes upon binding to the hormone ligand [77]. Androgens are essential steroid hormones for male sex development as well as the maintenance of male reproductive organs and spermatogenesis, through binding to AR $[78,79]$.

The total number of reported $A R$ mutations exceeds 1000 (many of them representing non-synonymous mutations altering the DNA binding site), with a wide spectrum of associated phenotypes ranging from the complete androgen insensitivity syndrome (phenotypic female 46, XY individuals) to a mild form of androgen insensitivity in azoospermic males with apparently normal testes [80].

Mutant mice for this gene exhibit pathological phenotypes similar to those observed in humans [81]. Interestingly, conditional knock-out mice in which $A r$ was selectively depleted in Sertoli cells showed meiotic arrest in spermatocytes, thus highlighting the relevant role that androgens may have for the spermatogenic function [82].

$A R$ is a highly polymorphic gene that contains two variable number tandem repeats (VNTRs), $(\mathrm{CAG})_{\mathrm{n}}$ and $(\mathrm{CGN})_{\mathrm{n}}$ (encoding for glycine and glutamine, respectively) in the $\mathrm{N}$-terminal domain (located in exon1) [83]. The length of the CAG repeats has been associated with different human disorders, including impaired sperm production and male infertility [84]. In this regard, the possible implication of the CAG repeat in the development of NOA has been extensively investigated [85]. Although the results have been controversial in some cases, it has been proposed that long CAG repeats may increase the predisposition of male infertility due to impaired androgen function [86,87].

\subsubsection{NR5A1}

The protein encoded by NR5A1 (nuclear receptor subfamily 5, group A, member 1, MIM*184757), also known as SF1 and $A D 4 B P$, belongs to the family of nuclear receptors, which has a central role in many aspects of tissue development and function [88]. The expression of this gene was initially located in the main steroidogenic tissues of the adult mouse (adrenal cortex, testis, and ovary), related to the synthesis of steroids. Shortly after, it was discovered that it also played an important role in the synthesis of gonadotropins as well as in sex differentiation and development of both the gonad and the adrenal gland [89-94]. Indeed, the SF-1 protein is a transcription factor that modulates the timing and expression levels of many target genes, including key players of the hypothalamic-pituitary-steroidogenic axis [95].

Mutations of Nr5a1 in mouse models cause abnormal development of the hypothalamus and pituitary gland, showing absence of both luteinizing and follicle-stimulating hormones [93]. Knock-out mice are born at the expected age, but shortly after birth they die due to adrenocortical insufficiency. These mice lack adrenal glands and gonads, and XY individuals develop Mullerian ducts resulting in internal female genitals $[94,96]$.

In humans, different clinical conditions have been associated with autosomal dominant mutations of NR5A1, including primary adrenal insufficiency, primary ovarian insufficiency, and different alterations of male sexual development, such as $46, \mathrm{XY}$ sex reversal, anorchidism, hypospadias, testicular dysgenesis, and spermatogenic failure [97].

Regarding NOA, in 2010 Bashamboo and colleagues [98] screened the coding sequence of NR5A1 in a population of mixed ancestry composed of 315 men with idiopathic spermatogenic failure and 729 healthy controls (359 normozoospermic men and 370 males with self-reported paternity of at least two children). Interestingly, they identified heterozygous missense mutations in four azoospermic individuals (3.9\% of all azoospermic men analysed) and two patients with severe oligospermia ( $4.3 \%$ of men with this phenotype). Noteworthy, the control population did not show any rare variation, and the described mutations were not found in more than 2100 additional control samples.

Three years later, the Tuttelmann's group conducted a similar study in a German cohort of 478 patients with diagnosis of spermatogenic failure ( 270 with NOA and 218 with severe oligospermia) and 237 men with normal semen parameters [99]. The authors identified three additional heterozygous 
missense mutations with predicted pathogenicity in protein function (one of them in an NOA patient). Several synonymous mutations were also observed, although they were present in some control individuals.

In 2015, two studies reported additional heterozygous NR5A1 non-synonymous mutations in NOA patients. Ferlin and collaborators [100] observed seven novel NR5A1 missense mutations in Italian subjects with severe spermatogenic impairment, three of them carried by NOA patients (one with idiopathic NOA and two with unilateral cryptorchidism). Similarly, two Iranian NOA patients were reported to harbour heterozygous NR5A1 missense mutations out of 90 azoospermic patients analysed [101]. In either study, no mutations were detected in fertile individuals, with or without history of cryptorchidism [100,101].

In contrast with the previously mentioned studies, in a recent screening on the Indian population, no mutations within NR5A1 were detected in 414 NOA patients [102].

\subsubsection{DMRT1}

DMRT1 (doublesex- and MAB3-related transcription factor 1, MIM*602424) belongs to the DMRT family, which encodes a group of highly conserved transcription factors involved in sex determination and gonadal development of several metazoan phyla [103]. This gene family represented the first described case of sex regulatory genes in both vertebrates and invertebrates [104,105]. DMRT1 expression is detected in pre-Sertoli cells of the undifferentiated gonads shortly after male sex determination (at the sixth week of pregnancy). Its expression remains active until adulthood, representing a Sertoli cell marker [106].

Subtelomeric deletions of the short arm of the human chromosome 9 (in which DMRT1 is located) have been associated with 46, XY sex reversal and gonadal dysgenesis in XY individuals [107]. Interestingly, smaller deletions encompassing DMRT1 were identified in five infertile men with azoospermia but no symptoms of gonadal dysgenesis.

Unexpectedly, the experimental removal of Dmrt 1 from the mouse genome caused no abnormalities in either sex determination or the embryonic gonadal development. However, the testes of those mice during postnatal development underwent rapid deformation due to a failure in the differentiation of Sertoli cells, which showed uncontrolled proliferation and, finally, apoptosis. The germ cells, in turn, did not migrate to the periphery of the seminiferous tubules and died also shortly after birth [108].

In relation to NOA, in 2013 Lopes and colleagues [109] identified deletions of the DMRT1 exonic sequence in five subjects diagnosed with idiopathic NOA (two Europeans and three Han Chinese) from a total cohort of 1423 azoospermic patients (323 Europeans and 979 Chinese) and 2834 fertile controls (1100 Europeans and 1734 Chinese), through the analysis of large-scale genotyping data. Interestingly, one of these individuals showed SCO.

One year later, Tewes and colleagues [110] analysed the DMRT1 sequence in 131 individuals diagnosed with NOA and 215 normozoospermic controls, reporting two cases of NOA (one of them with SCO) that showed heterozygosity for a putative pathogenic transition mutation in the third exon of the gene. The DMRT1 mutation observed in the SCO patient was detected in another NOA individual from Brazil (from a total of 16 azoospermic patients analysed) in a recent study [111].

Finally, in 2015, the Lopes' group identified three additional noncoding variants located in regulatory regions of DMRT1, by analysing a Portuguese study cohort of 155 NOA and 376 controls (75 normozoospermic and 301 with self-reported fatherhood) using a multiplex ligation probe assay and Sanger sequencing [112]. One of them, located in the promoter region, showed clear evidence of a key regulatory role in Dmrt1 repression. In addition, the frequency of some coding and noncoding DMRT1 rare variants were also significantly higher in the NOA group compared with the control one.

\subsubsection{TEX11}

TEX11 (testis-expressed gene 11, MIM*300311) was discovered in 2001 through cDNA subtraction of specific transcripts of mouse spermatogonia that were not present in somatic cells [113]. It 
encodes a highly conserved meiosis-specific protein involved in the assembly and maintenance of the synaptonemal complex during chromosome recombination in prophase I. Indeed, mutant mice for Tex11 exhibited achiasmate chromosomes as well as impaired double-strand break repair and chromosomal crossover [114]. Notably, TEX11 is an X-linked gene, which indicates the important role that this sex chromosome may have in spermatogenesis.

In 2015, Yatsenko and colleagues [115] reported a hemizygous deletion of three exons of TEX11 (encoding a fragment of the meiosis-specific domain SPO22) in two NOA patients. In a subsequent step, the authors performed a comprehensive mutation screening that revealed additional TEX11 mutations, including non-synonymous changes of the coding sequence and splicing mutations, in 7 out of 289 analysed NOA individuals. Interestingly, five of these patients harbouring TEX11 mutations had a meiotic arrest (representing $15 \%$ of all patients with meiotic arrest in the study population) that resembled the abnormal phenotype observed in mutant mice [114]. No single mutation was observed in any SCO patient or in 384 normozoospermic controls. In addition, the authors confirmed the expression of TEX11 in late-pachytene spermatocytes and in spermatids, being completely absent in Sertoli cells [115].

The high relevance of TEX11 in NOA was further confirmed in different independent sequencing studies [116-119], as well as in gene expression studies that reported a downregulation of TEX11 in testis samples from MA patients compared to controls [120].

\subsubsection{TEX14 and TEX15}

TEX14 (testis-expressed gene 14, MIM*605792) and TEX15 (testis-expressed gene 15, MIM*605795) represent two additional spermatogonium-specific genes identified by Wang et al. [113]. However, contrary to TEX11, these two genes have an autosome location (chromosomes 17q22 and 8p12, respectively), implying a double dosage in males. TEX14 encodes a protein kinase that is expressed almost exclusively in male spermatogonia, in which it seems to regulate their differentiation [121-123], whereas TEX15 encodes a protein with a function similar to that of TEX11 (double-strand DNA break repair and chromosomal synapsis) that has been detected in both testis and ovaries [124]. Knock-out mice for these two genes show spermatogenic failure at different levels (disruption of spermatogenesis before the completion of the first meiotic division in Tex14 null mice, and meiotic arrest in Tex15 null mice) $[121,124]$.

In humans, different mutations of both genes have been recently described in NOA patients. Two NOA brothers contained a 10 bp deletion within TEX14 that led to a truncated protein. Consistent with the observations in animal models, the germ line population of both brothers consisted mostly of undifferentiated spermatogonia [125]. In addition, Fakhro and collaborators [123] used whole-exon sequencing in eight consanguineous families and described a deleterious recessive mutation within TEX14 that segregated with disease. Regarding TEX15, three studies reported mutations associated with NOA. Okutman and colleagues [126] identified a heterozygous nonsense mutation in three Turkish brothers diagnosed with NOA and showing meiotic arrest, resulting in the generation of a premature stop codon. Colombo and colleagues [127] performed exome sequencing in two infertile siblings affected by NOA, identifying another nonsense mutation and a single nucleotide deletion that led to premature stop codons in the TEX15 locus. Finally, the recent sequencing study of 16 Brazilian patients affected by NOA by Araujo et al. [111] also reported novel rare variants in both TEX14 and TEX15.

\subsubsection{NPAS2}

NPAS2 (neuronal PAS domain protein 2, MIM*603347) encodes a transcription factor of the basic helix-loop-helix-PAS (bHLH-PAS) family that is mostly expressed in the central nervous system, in which it seems to regulate the circadian rhythms of the forebrain by interacting with the circadian locomotor output cycles kaput (CLOCK) proteins [128,129]. In 2015, Ramasamy and colleagues [130] analysed a consanguineous Turkish family, which included three infertile brothers affected by NOA, 
and identified a missense mutation located in exon 14 of NPAS2. Notably, a family segregation was observed, as all three siblings were homozygous for the mutation, whereas the mother and a fourth, fertile brother were heterozygous. Besides, the NPAS2 mutation was not detected in a control population of 50 fertile men. The authors proposed that the pathogenic effect of this mutation could be related to a disruption in steroidogenesis, by affecting the interaction of NPAS2 with circadian molecules like CLOCK.

\subsubsection{Other Putative Nonobstructive Azoospermia Genes}

Additional genes involved in spermatogenesis have been also proposed as single molecular causes of NOA, but, in most cases, further functional and/or validation studies are required to confirm the original findings. Some examples include SOHLH1 (spermatogenesis- and oogenesis-specific basic helix-loop-helix protein 1, MIM*610224) [117,131], USP26 (ubiquitin-specific protease 26, MIM*300309) [132,133], SYCP3 (synaptonemal complex protein 3, MIM*604759) [134], MEIOB (meiosis-specific protein with OD domains, MIM*617670), DNAH6 (dynein, axonemal, heavy chain 6, MIM*603336) [125], ZMYND15 (zinc finger MYND-containing protein 15, MIM*614312), TAF4B (TATA box-binding protein-associated factor, MIM*601689) [135], SYCE1 (synaptonemal complex central element protein 1, MIM*611486) [136], MCM8 (minichromosome maintenance complex component 8 , MIM*608187) [137], HSF2 (heat-shock transcription factor 2, MIM*140581) [138], SPINK2 (serine protease inhibitor, KAZAL-type, 2) [139], and TDRD9 (TUDOR domain-containing protein 9, MIM*617963) [140], amongst others [75] (Figure 1).

\section{Common Variation Associated with Susceptibility to Nonobstructive Azoospermia}

Despite the great progress made during the golden era of NGS in the elucidation of the genetic causes of azoospermia, there remains a considerably large proportion of missing heritability that still needs to be accounted for. Indeed, in a large proportion of patients with spermatogenic disturbances, the aetiology remains unknown [141]. Many studies have been performed to shed light into the so-called idiopathic NOA, but, in most cases, they have been strongly limited by low sample sizes and heterogeneous inclusion criteria of the study groups [85,142] (Table 1).

\subsection{Candidate Gene Approach}

During the last three decades, big efforts have been made to identify candidate gene polymorphisms associated with a complex form of idiopathic NOA. SNPs have been the most analysed variations, with some studies on VNTRs and CNVs. Selected genes include those involved in hormone production, regulation of the cell cycle, and spermatogenesis [85,142]. Although some significant genetic associations with spermatogenic failure have been published (mainly within regulatory genes of meiosis), most candidate gene studies have been performed in Asian populations and either lack validation in replication cohorts or show conflicting results (Table 1). The main reasons for such inconsistency are (1) the extremely reduced case/control cohort sizes analysed, which had led most likely to many type I and II errors in statistical hypothesis testing, and (2) the poor clinical characterisation of the patients included. Replicated associations of NOA-specific candidate genes include $A R$ (see above) [143,144], PIWIL4 (PIWI-like 4, MIM*610315, encoding a key molecule for retrotransposon silencing in the germ line) [145-147], MTHFR (methylenetetrahydrofolate reductase, MIM*607093; an important regulatory gene involved in folate metabolism) [148-150], MTR (5-methyltetrahydrofolate-homocysteine S-methyltransferase, MIM $^{*} 156570$; responsible for the regeneration of methionine from homocysteine by transferring of a methyl group) [149,151], NOS3 (nitric oxide synthase 3, MIM*163729; involved in the release of nitric oxide for the regulation of the reproductive function) [152,153], and H2BFWT (H2B histone family, member W, testis-specific, MIM*300507, a testis-specific histone variant gene related to spermatogenesis) [154-156]. 
Table 1. Common genetic variations associated with nonobstructive azoospermia through association studies.

\begin{tabular}{|c|c|c|c|c|c|c|c|c|c|c|c|c|c|}
\hline Year & Risk Loci & $\begin{array}{c}\text { Variant } \\
\text { ID }\end{array}$ & $\begin{array}{c}\text { Variant } \\
\text { Type }\end{array}$ & $\begin{array}{c}\text { Position } \\
\text { (GRCh38) }\end{array}$ & $\begin{array}{l}\text { Functional } \\
\text { Annotation }\end{array}$ & Population & $\begin{array}{l}\text { Cohort Size } \\
\text { (Case/Control) }\end{array}$ & $p$-Value & OR (CI 95\%) & $\begin{array}{c}\text { Associated } \\
\text { Trait }\end{array}$ & Strategy & Reference & Replication \\
\hline 1999 & $A R$ & $(\mathrm{CAG}) \mathrm{n}$ & $\mathrm{CNV}$ & $X: 67545318$ & Exonic & Japanese & $41 / 48$ & 0.0013 & NA & NOA & Candidate gene & Yoshida et al. [157] & YES \\
\hline 2003 & MTHFR & rs1801133 & SNV & 1:11796321 & Missense & Italian & $21 / 105$ & NA & NA & NOA & Candidate gene & Stuppia et al. [148] & YES \\
\hline 2006 & MEI1 & rs2050033 & SNV & 22:41763225 & Synonymous & European/Israeli & $26 / 121$ & $0.027^{*, *, *, *}$ & NA & MA & Candidate gene & Sato et al. [158] & NO \\
\hline 2006 & MTR & rs1805087 & SNV & 1:236885200 & Missense & South Korean & $174 / 325$ & $0.0063^{*, *}$ & $4.63(1.40-15.31)$ & NOA & Candidate gene & Lee et al. [151] & YES \\
\hline 2010 & PACRG & rs9347683 & SNV & 6:162728023 & $5^{\prime}$-UTR & Australian & $206 / 156$ & 0.009 & $1.60(1.13-2.36)$ & NOA & Candidate gene & Wilson et al. [159] & NO \\
\hline 2010 & $B C L 2$ & rs1800477 & SNV & $18: 63318540$ & Missense & Han Chinese & $198 / 183$ & 0.01 * & $0.45(0.23-0.89)$ & $\mathrm{NOA}$ & Candidate gene & Ma et al. [160] & NO \\
\hline 2010 & KDM3A & rs34605051 & SNV & $2: 86466703$ & Missense & European & $80 / 158$ & $3.23 \times 10^{-3 *, *}$ & NA & NOA & GWAS follow-up & Aston et al. [161] & NO \\
\hline 2010 & TAS2R38 & rs10246939 & SNV & 7:141972804 & Missense & European & $80 / 158$ & $7.24 \times 10^{-4}$ * & NA & NOA & GWAS follow-up & Aston et al. [161] & NO \\
\hline 2011 & MTHFR & rs1801131 & SNV & 1:11794419 & Missense & Brazilian & $55 / 173$ & 0.01 * & $0.34(0.16-0.74)$ & NOA & Candidate gene & Gava et al. [149] & YES \\
\hline 2011 & PEX10 & rs2477686 & SNV & $1: 2461209$ & Intergenic & Han Chinese & $2927 / 5734$ & $5.65 \times 10^{-12}$ & $1.39(1.26-1.52)$ & NOA & GWAS & Hu et al. [162] & NO \\
\hline 2011 & PRMT6 & rs12097821 & SNV & 1:106793679 & Intergenic & Han Chinese & $2927 / 5734$ & $5.67 \times 10^{-10}$ & $1.25(1.17-1.34)$ & NOA & GWAS & Hu et al. [162] & YES \\
\hline 2011 & SOX5 & rs10842262 & SNV & 12:24031610 & Intronic & Han Chinese & $2927 / 5734$ & $2.32 \times 10^{-9}$ & $1.23(1.15-1.32)$ & NOA & GWAS & Hu et al. [162] & YES \\
\hline 2012 & H2BFWT & rs7885967 & SNV & $\mathrm{X}: 104013669$ & $5^{\prime}$-UTR & Chinese & $204 / 209$ & 0.001 & $1.89(1.28-2.79)$ & NOA & Candidate gene & Ying et al. [154] & YES \\
\hline 2012 & HLA-DRA & rs3129878 & SNV & 6:32440958 & Intronic & Han Chinese & $2226 / 4576$ & $3.70 \times 10^{-16}$ & 1.37 (NA) & NOA & GWAS & Zhao et al. [163] & YES \\
\hline 2012 & TSBP1 & rs498422 & SNV & $6: 32318984$ & Intronic & Han Chinese & $2226 / 4576$ & $2.43 \times 10^{-12}$ & $1.42(\mathrm{NA})$ & NOA & GWAS & Zhao et al. [163] & YES \\
\hline 2013 & ATM & rs189037 & SNV & 11:108223106 & 5'-UTR & Chinese & $229 / 236$ & 0.003 & $1.41(1.11-1.78)$ & NOA & Candidate gene & Li et al. [164] & NO \\
\hline 2013 & NOS3 & rs2070744 & SNV & 7:150992991 & Intronic & Chinese & $151 / 246$ & $<0.001$ & $2.52(1.56-4.06)$ & $\mathrm{NOA}$ & Candidate gene & Ying et al. [152] & YES \\
\hline 2013 & NOS3 & rs61722009 & INDEL & 7:150997170 & Intronic & Chinese & $151 / 246$ & 0.001 & $2.27(1.39-3.72)$ & NOA & Candidate gene & Ying et al. [152] & YES \\
\hline 2014 & ABLIM1 & rs7099208 & SNV & 10:114894815 & Intronic & Han Chinese & $3608 / 5909$ & $6.41 \times 10^{-14}$ & $1.41(1.29-1.54)$ & NOA & GWAS replication & Hu et al. [165] & YES \\
\hline 2014 & $B C L 2$ & $\begin{array}{l}\text { rs7226979 } \\
\text { - }\end{array}$ & SNV & $18: 63257737$ & Intronic & Han Chinese & $1653 / 2329$ & $4.50 \times 10^{-5}$ & $1.21(1.11-1.33)$ & NOA & GWAS replication & Qin et al. [166] & NO \\
\hline 2014 & CHD2 & rs140671 & SNV & 15:26976951 & Intronic & Han Chinese & $1653 / 2329$ & $1.70 \times 10^{-4}$ & $0.78(0.68-0.89)$ & NOA & GWAS replication & Qin et al. [166] & NO \\
\hline 2014 & GNAO1 & rs2126986 & SNV & 16:56317795 & Intronic & Han Chinese & $1653 / 2329$ & $2.30 \times 10^{-6}$ & $1.28(1.15-1.41)$ & NOA & GWAS replication & Qin et al. [166] & NO \\
\hline 2014 & HLA-DRA & rs7194 & SNV & 6:32444703 & $3^{\prime}$-UTR & Han Chinese & $3608 / 5909$ & $3.76 \times 10^{-19}$ & $1.30(1.23-1.38)$ & NOA & GWAS replication & Hu et al. [165] & YES \\
\hline 2014 & IL17A & rs13206743 & SNV & 6:52152310 & Intergenic & Han Chinese & $3608 / 5909$ & $3.69 \times 10^{-8}$ & $1.35(1.22-1.51)$ & NOA & GWAS replication & Hu et al. [165] & NO \\
\hline 2014 & PIWIL4 & rs508485 & SNV & 11:94621313 & 3'-UTR & Spanish & $22 / 56$ & 0.021 & NA & MA & Candidate gene & Muñoz et al. [145] & YES \\
\hline 2014 & SFRS4 & rs12046213 & SNV & 1:29186811 & Intergenic & Chinese & 962/1931 & 0.021 & $0.88(0.78-0.98)$ & NOA & Candidate gene & Ni et al. [167] & NO \\
\hline 2014 & SFRS6 & rs6103330 & SNV & 20:43458814 & Intronic & Chinese & 962/1931 & $2.78 \times 10^{-3}$ & $1.28(1.09-1.50)$ & NOA & Candidate gene & Ni et al. [167] & NO \\
\hline 2014 & SFRS9 & rs17431717 & SNV & 12:120474407 & Intronic & Chinese & 962/1931 & 0.035 & $0.73(0.54-0.98)$ & NOA & Candidate gene & Ni et al. [167] & NO \\
\hline 2014 & SFRSG & rs10849753 & SNV & 12:120473010 & Intronic & Chinese & $962 / 1931$ & $4.32 \times 10^{-3}$ & $1.17(1.05-1.31)$ & NOA & Candidate gene & Ni et al. [167] & NO \\
\hline 2014 & SPO11 & rs28368082 & SNV & 20:57335452 & Missense & Iranian & $58 / 50$ & 0.006 & $6.68(\mathrm{NA})$ & $\mathrm{NOA}$ & Candidate gene & Ghalkhani et al. [168] & NO \\
\hline 2015 & GSTP1 & rs1695 & SNV & $11: 67585218$ & Missense & Chinese & $361 / 234$ & $0.023 *$ & $1.48(1.06-2.07)$ & NOA & Candidate gene & Xiong et al. [169] & NO \\
\hline 2015 & USF1 & rs2516838 & SNV & 1:161044580 & Intronic & Chinese & $361 / 368$ & 0.02 & $1.43(1.06-1.95)$ & NOA & Candidate gene & Zhang et al. [170] & NO \\
\hline 2015 & EPSTI1 & rs12870438 & SNV & 13:42906069 & Intronic & Japanese & 76/791 & 0.0059 & $1.92(1.21-3.05)$ & $\mathrm{NOA}$ & Candidate gene & Sato et al. [171] & NO \\
\hline 2015 & FSHR & rs6165 & SNV & 2:48963902 & Missense & Iranian & $126 / 86$ & 0.001 & $2.06(1.36-3.12)$ & NOA & Candidate gene & Gharesi-Fard et al. [172] & NO \\
\hline 2015 & MLH3 & rs175080 & SNV & $14: 75047125$ & Missense & Chinese & $244 / 614$ & $<0.001$ & $1.75(1.27-2.41)$ & $\mathrm{NOA}$ & Candidate gene & Zhang et al. [173] & NO \\
\hline 2015 & MTHFR & rs55763075 & SNV & 1:11790377 & $3^{\prime}-\mathrm{UTR}$ & Chinese & $253 / 458$ & 0.043 & $1.27(1.01-1.58)$ & $\mathrm{NOA}$ & Candidate gene & Zhang et al. [174] & NO \\
\hline 2015 & SOHLH2 & rs1328626 & SNV & 13:36204635 & Intronic & Chinese & $361 / 368$ & 0.038 & $0.80(0.65-0.99)$ & NOA & Candidate gene & Song et al. [175] & NO \\
\hline 2015 & SOHLH2 & rs6563386 & SNV & 13:36202894 & Intronic & Chinese & $361 / 368$ & 0.029 & $1.40(1.03-1.90)$ & NOA & Candidate gene & Song et al. [175] & NO \\
\hline 2016 & HSA-miR-196a & rs11614913 & SNV & 12:53991815 & Intergenic & Chinese & $140 / 486$ & $0.009 *$ & $1.76(1.15-2.70)$ & NOA & Candidate gene & Lu et al. [176] & NO \\
\hline 2016 & NR3C1 & rs852977 & SNV & 5:143307929 & Intronic & Japanese & $335 / 410$ & $5.70 \times 10^{-15}$ & $3.20(2.40-4.26)$ & NOA & Candidate gene & Chihara et al. [177] & NO \\
\hline 2016 & TDRD1 & rs77559927 & SNV & 10:114179297 & $5^{\prime}$-UTR & Chinese & $342 / 493$ & $0.03^{*}$ & $0.73(0.56-0.97)$ & NOA & Candidate gene & Zhu et al. [178] & NO \\
\hline 2016 & YBX2 & rs222859 & SNV & 17:7294475 & Missense & Iranian & $60 / 96$ & $<0.05^{*, *, *}$ & $0.23(0.12-0.6)$ & $\mathrm{NOA}$ & Candidate gene & Najafipour et al. [179] & NO \\
\hline 2017 & CYP1A1 & rs4646903 & SNV & $15: 74719300$ & Intergenic & South Indian & $120 / 80$ & $0.0001 *$ & $3.71(2.05-6.74)$ & NOA & Candidate gene & Ramgir et al. [180] & NO \\
\hline 2017 & FASL & $\begin{array}{l}\text { rs763110 } \\
\text { s }\end{array}$ & SNV & 1:172658358 & Intergenic & Iranian & $102 / 110$ & $0.02^{*, *, *}$ & NA & NOA & Candidate gene & Asgari et al. [181] & NO \\
\hline 2017 & PRKDC & rs7003908 & SNV & 8:47858141 & Intronic & Iranian & $102 / 214$ & 0.03 & $1.51(1.04-2.18)$ & NOA & Candidate gene & Jahantigh et al. [182] & NO \\
\hline 2017 & TNFR1 & rs767455 & SNV & $12: 6341779$ & Synonymous & Iranian & $108 / 119$ & $<0.001$ & $2.30(1.58-3.36)$ & NOA & Candidate gene & Ashrafzadeh et al. [183] & NO \\
\hline 2017 & XRCC5 & rs6147172 & VNTR & 2:216109147 & Promoter & Iranian & $102 / 214$ & 0.001 & $0.43(0.26-0.73)$ & NOA & Candidate gene & Jahantigh et al. [182] & NO \\
\hline 2017 & XRCC6 & rs2267437 & SNV & 22:41620695 & Intronic & Iranian & $102 / 214$ & 0.0002 & $1.94(1.37-2.75)$ & $\mathrm{NOA}$ & Candidate gene & Jahantigh et al. [182] & NO \\
\hline 2018 & DICER1 & rs1057035 & SNV & 14:95087805 & $3^{\prime}$-UTR & Iranian & $135 / 120$ & $<0.05$ & $1.49(1.27-1.88)$ & NOA & Candidate gene & Moghbelinejad et al. [184] & NO \\
\hline
\end{tabular}


Table 1. Cont

\begin{tabular}{|c|c|c|c|c|c|c|c|c|c|c|c|c|c|}
\hline Year & Risk Loci & $\begin{array}{l}\text { Variant } \\
\text { ID }\end{array}$ & $\begin{array}{l}\text { Variant } \\
\text { Type }\end{array}$ & $\begin{array}{l}\text { Position } \\
\text { (GRCh38) }\end{array}$ & $\begin{array}{l}\text { Functional } \\
\text { Annotation }\end{array}$ & Population & $\begin{array}{l}\text { Cohort Size } \\
\text { (Case/Control) }\end{array}$ & $p$-Value & OR (CI 95\%) & $\begin{array}{c}\text { Associated } \\
\text { Trait }\end{array}$ & Strategy & Reference & Replication \\
\hline 2018 & DPF3 & rs10129954 & SNV & 14:72683993 & Intronic & Japanese & $83 / 713$ & $7.40 \times 10^{-3}$ & $2.05(1.21-3.46)$ & NOA & Candidate gene & Sato et al. [185] & NO \\
\hline 2018 & H2BFWT & rs553509 & SNV & X:104013293 & Missense & Iranian & $120 / 250$ & 0.019 & $1.69(1.09-2.62)$ & NOA & Candidate gene & Teimouri et al. [186] & NO \\
\hline 2018 & IL1A & $\begin{array}{l}\text { rs2071376 } \\
\text { lats }\end{array}$ & SNV & 2:112777818 & Intronic & Iranian & $230 / 230$ & 0.034 & $1.67(1.04-2.68)$ & NOA & Candidate gene & Zamani-Badi et al. [187] & NO \\
\hline 2018 & IL1A & rs17561 & SNV & 2:112779646 & Missense & Iranian & $230 / 230$ & $<0.0001$ & $2.59(1.67-4.04)$ & NOA & Candidate gene & Zamani-Badi et al. [188] & NO \\
\hline 2018 & RNF212 & rs4045481 & SNV & 4:1096837 & Synonymous & Chinese & $220 / 248$ & 0.003 & $1.50(1.15-1.95)$ & NOA & Candidate gene & Yu et al. [189] & NO \\
\hline 2019 & ERCC2 & 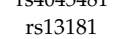 & SNV & $\begin{array}{l}\text { 4.1090037 } \\
\text { 19:45351661 }\end{array}$ & $\begin{array}{l}\text { Missense } \\
\text { Mens }\end{array}$ & Indo-European & $541 / 416$ & $0.03^{*} *, *, *, *$ & $1.59(1.04-2.42)$ & NOA & Candidate gene & Singh et al. [190] & NO \\
\hline 2019 & FSHB & rs10835638 & SNV & 11:30230805 & Intergenic & German & 659 & $0.017^{*, *, *, *, *, *}$ & $0.20(0.06-0.70)$ & TESE- & Candidate gene & Busch et al. [191] & NO \\
\hline 2019 & MSH3 & $\begin{array}{l}\text { rs26279 } \\
\text { res }\end{array}$ & SNV & $5: 80873118$ & Missense & Northwest Chinese & $131 / 201$ & $<0.05^{*, *}$ & $2.62(1.05-6.57)$ & NOA & Candidate gene & Zhao et al. [192] & NO \\
\hline 2019 & $H L A-B$ & rs4997052 & SNV & 6:31356367 & Missense & Han Chinese & $981 / 1657$ & $2.26 \times 10^{-5}$ & $1.30(1.15-1.46)$ & NOA & GWAS imputation & Huang et al. [193] & NO \\
\hline 2020 & STAG3 & rs1727130 & SNV & $7: 100213841$ & Intronic & Korean & $77 / 245$ & $0.039 *$ & $1.64(1.03-2.61)$ & NOA & Candidate gene & Nam et al. [194] & NO \\
\hline 2020 & STAG3 & rs1052482 & SNV & $7: 100214213$ & $3^{\prime}$-UTR & Korean & $77 / 245$ & $0.039 *$ & $1.64(1.03-2.61)$ & NOA & Candidate gene & Nam et al. [194] & NO \\
\hline
\end{tabular}

$p$-values of the allelic test are shown except for ${ }^{*}$ dominant model of the minor allele; ${ }^{* * *}$ recessive model of the minor allele; ${ }^{*, *, *}$ genotypic (2-df) model; ${ }^{*, *, *, *}$ codominant model; and *,*,*,*,* TTvsGG. CI, confidence interval; CNV, copy number variant; GWAS, genome-wide association study; INDEL, insertion/deletion variant; MA, meiotic arrest; OR, odds ratio; NOA, nonobstructive azoospermia; SNV, single-nucleotide variant; TESE-, unsuccessful testicular sperm extraction; UTR, untranslated region; VNTR, variable number tandem repeat. 


\subsection{Insights from Large-Scale Genetic Studies}

The development of high-throughput genotyping platforms was a breakthrough that allowed the investigation of the genetic basis of complex traits at a genome-wide level [195]. In particular, the genome-wide association studies (GWAS), in which genetic variation across the whole genome is interrogated in a hypothesis-free fashion, have represented a major advance in biomedical discovery [196]. However, as described below, the GWAS strategy has not been very useful to define the genetic component of NOA, mainly because of the strong limitations of the study designs.

\subsubsection{Pilot GWAS in Europeans}

The first GWAS of NOA was conducted in 2009 by Aston and Carrell [197]. In this study, 370,000 SNPs were analysed in 80 patients with spermatogenic impairment (52 with severe oligospermia and only 40 with NOA) and 80 normozoospermic controls of European descent. Such a small study cohort implied a statistical power close to zero, which prevented the authors from obtaining any relevant results. It should be noted that hundreds of thousands of independent tests are conducted in a GWAS. Hence, a $p$-value threshold for statistical significance of $5 \times 10^{-8}$ is required to control the (highly probable) type I errors in these types of studies [198-200]. Therefore, considerably large case/control populations are needed to discern disease-specific associations from the numerous false positive signals. Taking this into consideration, the authors performed a follow-up study in a slightly larger European population composed of 141 severe oligospermic individuals, 80 NOA patients, 63 moderately oligospermic individuals, and 158 normospermic controls. They analysed 172 candidate SNPs (based on both gene function and previously published reports of association with male infertility) and performed a combined analysis with their previous GWAS data [161]. The comparison of the NOA group against the control one evidenced suggestive associations just for two non-synonymous SNPs (rs34605051 and rs10246939) of the genes KDM3A (lysine-specific demethylase 3A, MIM* 611512; a histone demethylase involved in packaging and condensation of sperm chromatin) and TAS2R38 (taste receptor, type 2, member $38, \mathrm{MIM}^{*} 607751$; a surface protein of taste receptor cells with no reported function in the testis). Other SNPs showed significant P-values when NOA and severe oligospermia patients were analysed together, including two missense variants of TEX15 (rs323344 and rs323345) [161].

\subsubsection{First GWAS in East Asians}

The first well-powered GWAS was published in 2011 by Hu et al. [162]. The authors performed a three-stage study comprising a total of 2927 NOA patients and 5734 control subjects, all from the Han Chinese population. This study reported the first NOA associations at the genome-wide level of significance in the genomic regions of PRMT6 (protein arginine $N$-methyltransferase 6, MIM*608274; a methyltransferase expressed in spermatogonia), PEX10 (peroxisome biogenesis factor 10, $\mathrm{MIM}^{*} 602859$; a peroxisomal protein potentially involved in spermatogenesis), and SOX5 (SRY-BOX 5, MIM*604975; encoding a transcription factor restricted to post-meiotic germ cells during spermatogenesis). SOX5 was also associated to oligospermia in a subsequent study [201]. However, the NOA population of the GWAS included individuals with partial deletions of the AZF region, and the controls were not healthy (they were obtained from a lung cancer study) and lacked semen analysis, which could have influenced the final results [162]. Indeed, inconsistent results were obtained in different replication studies. Whereas the three NOA associations described in the GWAS failed to replicate in a population of 490 NOA patients and 1167 controls from Japan [202], both the PEX10 and SOX5 risk variants showed evidence of association with NOA in an independent study cohort from central China composed of 301 azoospermic cases and 720 normal controls [203].

In 2014, aimed to identify additional NOA susceptibility factors, the same group conducted an extended three-stage validation study of the GWAS in 3608 NOA cases (including the original GWAS cohort) and 5909 controls from China [165]. Genetic associations at the genome-wide level of significance 
were observed in three new loci: a genomic region near IL17A (interleukin 17A, MIM*603149; encoding a proinflammatory cytokine), ABLIM1 (actin-binding LIM protein family, member 1, MIM*602330; a regulatory gene of the actin-dependent signalling), and HLA-DRA (major histocompatibility complex, class II, DR alpha, MIM*142860; encoding the alpha subunit of the HLA-DR molecule). The two latter associations were further replicated in independent Chinese populations [204,205].

Another follow-up study of the GWAS was performed by Qin and colleagues in 2014 [166]. The authors obtained imputed genotypes from the original GWAS data and carried out a two-stage association study of 24,238 makers (selected for their location within genes of canonical pathways known to be important in spermatogenesis) in a Han Chinese case/control cohort comprising 1653 NOA cases and 2329 controls. The SNPs rs1406714 in CHD2 (chromodomain helicase DNA-binding protein $2, \mathrm{MIM}^{*} 602119$; which may play a role in the DNA damage response and genome stability maintenance), rs2126986 in GNAO1 (guanine nucleotide-binding protein, alpha-activating activity polypeptide $\mathrm{O}, \mathrm{MIM}^{*} 139311$; a member of guanine nucleotide binding proteins), and rs7226979 in BCL2 (B-cell CLL/lymphoma 2, MIM* 151430; encoding an apoptosis regulator) were identified as novel NOA risk variants. However, these associations have not been replicated in independent studies so far.

\subsubsection{Second GWAS in East Asians}

A second GWAS of NOA in the Han Chinese population was conducted by Zhao and collaborators in 2012 [163]. The study followed a three-stage approach, including a total of 2226 NOA cases and 4576 controls. Although the large sample set allowed the authors to perform the analyses with a considerably high statistical power, almost half of the control cohort included in the first stage was composed of women, representing an important limitation. Despite this, different association signals within the HLA region were associated with NOA risk at the genome-wide significance level. The strongest one corresponded to a haplotype block of the HLA-DRA locus, whose lead variant was rs3129878 (located in intron 1 of the gene). A second independent SNP (rs498422) located in the nearby gene TSBP1 (testis-expressed basic protein 1, MIM*618151; encoding a protein expressed in the testis with unknown function) was also detected. The associated HLA variants were described as tag SNPs of the classical allele $H L A-D R B^{*} 0405$. Therefore, this study highlighted the HLA system as a relevant player in the development of idiopathic NOA, likely by triggering autoimmune/autoinflammatory responses against germ cell antigens in pathogenic situations in which the blood-testis barrier could be damaged [206].

\subsubsection{Fine-Mapping of the Major Histocompatibility Complex Region}

In a recent study, Huang and colleagues aimed to fine-map the HLA association with NOA described in the two GWASs of the Han Chinese population [193]. With that purpose, they used a specific imputation method to infer classical HLA alleles, SNPs, and polymorphic amino acid positions using the data of the extended HLA region from the GWAS by Hu et al. [162]. The most statistically significant classical haplotype was HLA Class II $H L A-D R B 1^{*} 13: 02$, which had been reported before as an NOA risk allele in the Japanese population [207]. Additionally, two SNPs explained most of the HLA association with NOA, i.e., the HLA-DRA polymorphism rs7194 (reported as putative association marker in the two original GWASs) and the HLA-B polymorphism rs4997052, which represented a novel risk variant for NOA. The authors estimated that the proportion of phenotypic variance of NOA explained by these two HLA SNPs and the one established in the GWAS by Zhao [163] was between $0.5 \%$ and $1 \%$. Regarding the analysis at the amino acid level, position 55 of the HLA-DQB1 molecule represented the most statistically significant multiallelic site (Figure 2). Three possible residues were detected at that position: one of them representing a risk residue (arginine), another one representing a protective residue (leucine), and the third one with no effect on the susceptibility to NOA (proline). Other independently associated amino acid positions were HLA-DRB1*73 (with glycine conferring the higher risk) and HLA-B*166 (serine being the strongest risk residue). 


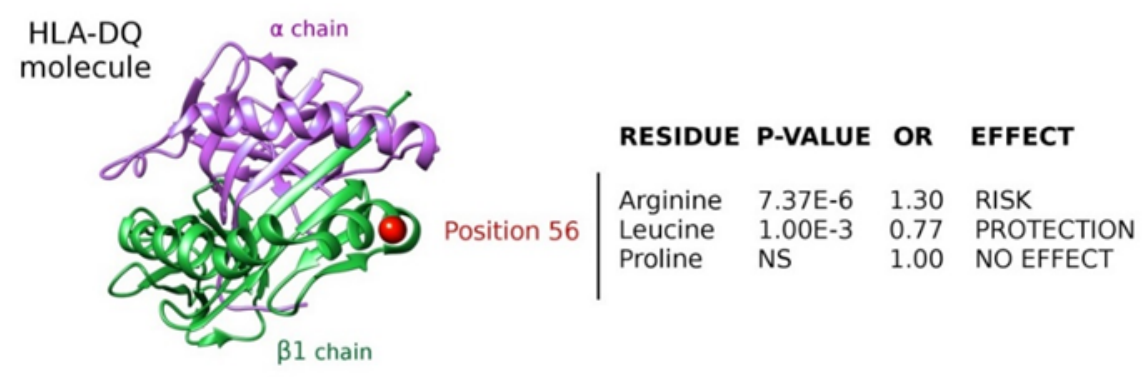

Figure 2. Ribbon representation of the HLA-DQ molecule. The most associated amino acid position with nonobstructive azoospermia susceptibility is highlighted with a red sphere. $P$-values, odds ratios (ORs), and the effect conferred by the different residues at that position are also shown. Data obtained from Huang et al. [193].

\subsubsection{GWAS in Hutterites}

Also in 2012, a GWAS of male infertility was performed in Hutterites (a North American ethnoreligious group of European ancestry that has large family sizes because contraception is proscribed) by Kosova and colleagues [208]. The authors tested for association with two heritable measures of fertility, family size and birth rate, in a random population of 269 married men. To validate the GWAS results, the most highly associated SNPs were genotyped in an independent population of 123 ethnically diverse male individuals from Chicago. However, because of the reduced statistical power of the study, no associated SNPs at the genome-wide level of significance were identified.

Subsequent candidate gene studies in Japanese were designed to evaluate the possible association with NOA susceptibility of the suggestive signals observed in the GWAS of the Hutterite population (those with P-values lower than $1 \times 10^{-4}$ ). The first of them was performed in 2015 and included a total of 917 Japanese subjects (76 NOA patients, 50 patients with oligospermia, and 791 fertile men) [171]. Interestingly, an intronic variant of EPSTI1 (epithelial stromal interaction 1, MIM*607441; encoding the epithelial stromal interaction protein 1, which is highly expressed in the testis) was associated with NOA at the study-wide level of significance after correction for multiple testing. The second study was also conducted by the same team three years later using the same case/control cohort [185]. In this case, a significant association was observed between an intronic variant of DPF3 (D4, zinc, and double PHD fingers family, member 3, MIM $^{*} 601672$; a transcription regulator involved in chromatin remodelling) and NOA risk.

\subsubsection{Other Genome-Wide Approaches}

Other large-scale approaches have been followed during the last years to shed light into the molecular causes of idiopathic NOA, including (1) an exome-wide association study that described three rare variants associated with NOA in the chromosome 6 genes HIST1H1E (histone gene cluster 1, H1 histone family, member E; MIM*142220; encoding the linker histone H1.4), FKBPL (FK506-binding protein-like, MIM*617076; which is involved in the steroid hormone signalling), and MSH5 (MutS homolog 5, MIM*603382; which plays a role in meiotic segregation fidelity and recombination) [209]; (2) different comparative genomic hybridization (CGH) studies that identified NOA-specific recurrent CNVs such as CNV67 (on Xq28), with potential clinical application [109,210-213]; (3) miRNA profiling in the seminal plasma, in which miR-141, miR-429, and miR-7-1-3p were significantly increased in NOA patients compared with fertile controls [214]; (4) a transcriptome-wide association study that established PILRA (paired immunoglobulin-like type 2 receptor, alpha, MIM*605341; potentially involved in the regulation of spermatogenesis and the blood-testis barrier) and ZNF676 (zinc finger protein 676; which may regulate the expression of genes associated with germ cell development) as putative novel NOA genes [215]; and (5) two genome-wide DNA methylation studies that identified NOA-specific methylation profiles in testicular tissues, including hyper-methylation of SOX30 (SRY-box 
30, MIM*606698; encoding an essential transcription factor for spermiogenesis) at the gene promoter, thus providing insight into the mechanisms underlying idiopathic NOA [216,217].

\section{Clinical Relevance of the Genetic Studies of Nonobstructive Azoospermia}

The rapid improvement of the new technologies for genetic analysis has enabled a substantial increase in our understanding of the aetiology of male infertility. However, the impact of such knowledge in the current genetic workup of azoospermic men is still limited, with very few novel findings incorporated to the genetic tests routinely used in clinical practice during the last two decades [24]. A genetic cause is normally identified in only $4 \%$ of infertile men, but this percentage increases to about $20 \%$ in azoospermic patients, thus highlighting the important contribution of genetic factors in the development of the most severe forms of male infertility [76]. This genetic influence is likely more relevant in NOA patients whose infertility causes remain idiopathic despite extensive laboratory evaluation.

As summarised above, increasing evidence points to idiopathic NOA as a complex and highly polygenic condition [218]. Because of that, the elucidation of its genetic component is highly demanded by thousands of urologists who have to deal with this condition on a day-to-day basis, as it may facilitate an appropriate clinical decision for enhancing fertility. Nevertheless, about 2000 genes have been proposed to be directly involved in the spermatogenic process, with more than 600 of them showing a specific expression in male germ cells [19,219-221]. This fact makes it extremely difficult to visualize the overall molecular picture of azoospermia, leading some authors to be skeptical about the feasibility of translating molecular genetic insights into clinical practice, especially those related to common variations of the human genome $[10,222,223]$.

Hopefully, a more optimistic scenario will be envisioned soon. There are some promising preliminary results supporting the important role that genetic testing may have in improving both care and counselling of patients diagnosed with idiopathic NOA [9]. For instance, Tüttelmann and colleagues have recently started to regularly analyse the gene sequence of NR5A1, DMRT1, and TEX11 in patients with idiopathic NOA, identifying causal pathogenic mutations in $5 \%$ of them and increasing the diagnostic efficiency to $25 \%$ in their study group [76]. In this sense, identifying a higher proportion of the heritability of spermatogenic impairment would definitively allow the development of broader diagnostic panels of genes, which could help (1) to achieve an accurate diagnosis, (2) to improve the selection criteria of spermatozoa for successful assisted reproduction techniques, reducing the possible genetic burden transmitted to the offspring, and (3) to estimate reliable personalized genetic scores with a prognostic value before counselling a patients to undergo testicular sperm retrieval or endocrine therapy $[23,224]$.

\section{Conclusions}

The development and widespread use of novel tools for genetic analysis has represented a turning point in the investigation of the genetic component of male infertility. In relation to NOA, the impact has been remarkable because azoospermic individuals are at the highest risk of harbouring genetic abnormalities. Consequently, many point mutations explaining specific cases of azoospermia are being increasingly reported, including paternal and de novo mutations in key genes involved in the testicular function. However, recent estimations suggest that around $75 \%$ of cases with severe spermatogenic impairment have an idiopathic origin [225]. In this regard, as discussed in this review, different lines of evidence suggest that, apart from those point mutations (which represent undoubtedly a primary cause of NOA in many patients), common variations of the human genome, mostly SNPs and $\mathrm{CNVs}$, may also have a role in the development of pathogenic mechanisms leading to spermatogenic failure. The concerns of some authors about this assumption rely on the inconsistency of some results obtained from case/control association studies. Nevertheless, it should be noted that NOA is a very heterogeneous condition, comprising different clinical entities (such as SCO, meiotic arrest, and hypospermatogenesis) with specific histological patterns and probably distinct aetiologies. This 
makes essential to establish stringent selection criteria for the study cohorts, which has not been possible in most studies. Besides, a low statistical power has represented an important limitation in the case/control analyses, especially in GWAS, which require considerably large sample sets to avoid type II errors. Therefore, it is imperative to reach a broad consensus on which clinical entities of NOA can be analysed in more homogeneous study groups. Certainly, this would require the establishment of large collaborative consortia that can join forces gathering well-powered case/control cohorts. Considering the current advances in assisted reproductive techniques, with most natural barriers for in vitro fertilisation and intracytoplasmic sperm injection being overcome, we need to focus now on identifying the pieces of the genetic puzzle of male infertility, which may include not only genes involved in testicular spermatogenesis, but also countless additional genes with roles in sperm maturation after exit from testes during epididymal passage. The development of effective genetic diagnostic and prognostic markers would be essential for counselling NOA patients with concerns about the causes of their infertility, the probability of success of testis sperm retrieval and in vitro fertilization, as well as the potential reproductive health of their children.

Author Contributions: Writing-Review and Editing, M.C., F.D.C., and R.P.; Visualization, F.D.C., R.P., and J.A.C.; Supervision, F.D.C. and R.P.; Project Administration, F.D.C., R.P., and J.A.C. All authors have read and agreed to the published version of the manuscript.

Acknowledgments: We thank Alejandro Fernández Sevilla for his valuable help in the development of Figure 2 of this review. The authors were funded by the Spanish Ministry of Economy and Competitiveness through the Spanish National Plan for Scientific and Technical Research and Innovation (ref. SAF2016-78722-R) and the "Ramón y Cajal" program (ref. RYC-2014-16458).

Conflicts of Interest: The authors declare no conflicts of interest.

\section{References}

1. Mascarenhas, M.N.; Flaxman, S.R.; Boerma, T.; Vanderpoel, S.; Stevens, G.A. National, regional, and global trends in infertility prevalence since 1990: A systematic analysis of 277 health surveys. PLoS Med. 2012, 9, e1001356. [CrossRef] [PubMed]

2. Chandra, A.; Copen, C.E.; Stephen, E.H. Infertility and impaired fecundity in the United States, 1982-2010: Data from the National Survey of Family Growth. Natl. Health Stat. Rep. 2013, 67, 1-18.

3. Jarow, J.P.; Espeland, M.A.; Lipshultz, L.I. Evaluation of the azoospermic patient. J. Urol. 1989, 142, $62-65$. [CrossRef]

4. Thonneau, P.; Marchand, S.; Tallec, A.; Ferial, M.L.; Ducot, B.; Lansac, J.; Lopes, P.; Tabaste, J.M.; Spira, A. Incidence and main causes of infertility in a resident population $(1,850,000)$ of three French regions (1988-1989). Hum. Reprod. 1991, 6, 811-816. [CrossRef] [PubMed]

5. Mazzilli, F.; Rossi, T.; Delfino, M.; Sarandrea, N.; Dondero, F. Azoospermia: Incidence, and biochemical evaluation of seminal plasma by the differential pH method. Panminerva Med. 2000, 42, 27-31. [PubMed]

6. Tuttelmann, F.; Werny, F.; Cooper, T.G.; Kliesch, S.; Simoni, M.; Nieschlag, E. Clinical experience with azoospermia: Aetiology and chances for spermatozoa detection upon biopsy. Int. J. Androl. 2011, 34, $291-298$. [CrossRef] [PubMed]

7. Agarwal, A.; Mulgund, A.; Hamada, A.; Chyatte, M.R. A unique view on male infertility around the globe. Reprod. Biol. Endocrinol. 2015, 13, 37. [CrossRef]

8. Esteves, S.C. Clinical management of infertile men with nonobstructive azoospermia. Asian J. Androl. 2015, 17, 459-470. [CrossRef]

9. Tournaye, H.; Krausz, C.; Oates, R.D. Novel concepts in the aetiology of male reproductive impairment. Lancet Diabetes Endocrinol. 2017, 5, 544-553. [CrossRef]

10. Krausz, C.; Riera-Escamilla, A. Genetics of male infertility. Nat. Rev. Urol. 2018, 15, 369-384. [CrossRef]

11. Brennan, J.; Capel, B. One tissue, two fates: Molecular genetic events that underlie testis versus ovary development. Nat. Rev. Genet. 2004, 5, 509-521. [CrossRef] [PubMed]

12. Phillips, B.T.; Gassei, K.; Orwig, K.E. Spermatogonial stem cell regulation and spermatogenesis. Philos. Trans. R. Soc. B Biol. Sci. 2010, 365, 1663-1678. [CrossRef] [PubMed] 
13. Potter, S.J.; DeFalco, T. Role of the testis interstitial compartment in spermatogonial stem cell function. Reproduction 2017, 153, R151-R162. [CrossRef] [PubMed]

14. Wu, S.; Yan, M.; Ge, R.; Cheng, C.Y. Crosstalk between Sertoli and Germ Cells in Male Fertility. Trends Mol. Med. 2019. [CrossRef]

15. Fayomi, A.P.; Orwig, K.E. Spermatogonial stem cells and spermatogenesis in mice, monkeys and men. Stem Cell Res. 2018, 29, 207-214. [CrossRef]

16. Larose, H.; Shami, A.N.; Abbott, H.; Manske, G.; Lei, L.; Hammoud, S.S. Gametogenesis: A journey from inception to conception. Curr. Top. Dev. Biol. 2019, 132, 257-310.

17. Shiraishi, K. Hormonal therapy for non-obstructive azoospermia: Basic and clinical perspectives. Reprod. Med. Biol. 2015, 14, 65-72. [CrossRef]

18. Younes, A.H.; Hamed, H.B.; Mohamed, E.M.; Makki, M.A.; Gaber, N.; Mohamed, H.M. Oestrogen receptors beta genotype in infertile Egyptian men with nonobstructive azoospermia. Andrologia 2016, 48, 1289-1293. [CrossRef]

19. Schultz, N.; Hamra, F.K.; Garbers, D.L. A multitude of genes expressed solely in meiotic or postmeiotic spermatogenic cells offers a myriad of contraceptive targets. Proc. Natl. Acad. Sci. USA 2003, 100, 12201-12206. [CrossRef]

20. Gunes, S.; Al-Sadaan, M.; Agarwal, A. Spermatogenesis, DNA damage and DNA repair mechanisms in male infertility. Reprod. Biomed. Online 2015, 31, 309-319. [CrossRef]

21. Robles, V.; Herraez, P.; Labbe, C.; Cabrita, E.; Psenicka, M.; Valcarce, D.G.; Riesco, M.F. Molecular basis of spermatogenesis and sperm quality. Gen. Comp. Endocrinol. 2017, 245, 5-9. [CrossRef] [PubMed]

22. Jungwirth, A.; Giwercman, A.; Tournaye, H.; Diemer, T.; Kopa, Z.; Dohle, G.; Krausz, C.; European Association of Urology Working Group on Male Infertility. European Association of Urology guidelines on Male Infertility: The 2012 update. Eur. Urol. 2012, 62, 324-332. [CrossRef] [PubMed]

23. Berookhim, B.M.; Schlegel, P.N. Azoospermia due to spermatogenic failure. Urol. Clin. N. Am. 2014, 41, 97-113. [CrossRef] [PubMed]

24. Barratt, C.L.R.; Bjorndahl, L.; De Jonge, C.J.; Lamb, D.J.; Osorio Martini, F.; McLachlan, R.; Oates, R.D.; van der Poel, S.; St John, B.; Sigman, M.; et al. The diagnosis of male infertility: An analysis of the evidence to support the development of global WHO guidance-challenges and future research opportunities. Hum. Reprod. Update 2017, 23, 660-680. [CrossRef]

25. Palermo, G.D.; Colombero, L.T.; Hariprashad, J.J.; Schlegel, P.N.; Rosenwaks, Z. Chromosome analysis of epididymal and testicular sperm in azoospermic patients undergoing ICSI. Hum. Reprod. 2002, 17, 570-575. [CrossRef]

26. Chandley, A.C. Infertility and chromosome abnormality. Oxf. Rev. Reprod. Biol. 1984, 6, 1-46.

27. Rivas, F.; Garcia-Esquivel, L.; Diaz, M.; Rivera, H.; Cantu, J.M. Cytogenetic evaluation of 163 azoospermics. J. Genet. Hum. 1987, 35, 291-298.

28. Yatsenko, A.N.; Yatsenko, S.A.; Weedin, J.W.; Lawrence, A.E.; Patel, A.; Peacock, S.; Matzuk, M.M.; Lamb, D.J.; Cheung, S.W.; Lipshultz, L.I. Comprehensive 5-year study of cytogenetic aberrations in 668 infertile men. J. Urol. 2010, 183, 1636-1642. [CrossRef]

29. Bojesen, A.; Gravholt, C.H. Klinefelter syndrome in clinical practice. Nat. Clin. Pract. Urol. 2007, 4, $192-204$. [CrossRef]

30. Denschlag, D.; Tempfer, C.; Kunze, M.; Wolff, G.; Keck, C. Assisted reproductive techniques in patients with Klinefelter syndrome: A critical review. Fertil. Steril. 2004, 82, 775-779. [CrossRef]

31. Tiepolo, L.; Zuffardi, O. Localization of factors controlling spermatogenesis in the nonfluorescent portion of the human Y chromosome long arm. Hum. Genet. 1976, 34, 119-124. [CrossRef] [PubMed]

32. Vogt, P.H.; Edelmann, A.; Kirsch, S.; Henegariu, O.; Hirschmann, P.; Kiesewetter, F.; Köhn, F.M.; Schill, W.B.; Farah, S.; Ramos, C.; et al. Human Y chromosome azoospermia factors (AZF) mapped to different subregions in Yq11. Hum. Mol. Genet. 1996, 5, 933-943. [CrossRef] [PubMed]

33. Ma, K.; Sharkey, A.; Kirsch, S.; Vogt, P.; Keil, R.; Hargreave, T.B.; McBeath, S.; Chandley, A.C. Towards the molecular localisation of the AZF locus: Mapping of microdeletions in azoospermic men within 14 subintervals of interval 6 of the human Y chromosome. Hum. Mol. Genet. 1992, 1, 29-33. [CrossRef] [PubMed] 
34. Repping, S.; Skaletsky, H.; Lange, J.; Silber, S.; Van Der Veen, F.; Oates, R.D.; Page, D.C.; Rozen, S. Recombination between palindromes P5 and P1 on the human Y chromosome causes massive deletions and spermatogenic failure. Am. J. Hum. Genet. 2002, 71, 906-922. [CrossRef] [PubMed]

35. Krausz, C.; Casamonti, E. Spermatogenic failure and the Y chromosome. Hum. Genet. 2017, 136, 637-655. [CrossRef] [PubMed]

36. Kamp, C.; Hirschmann, P.; Voss, H.; Huellen, K.; Vogt, P.H. Two long homologous retroviral sequence blocks in proximal Yq11 cause AZFa microdeletions as a result of intrachromosomal recombination events. Hum. Mol. Genet. 2000, 9, 2563-2572. [CrossRef]

37. Blanco, P.; Shlumukova, M.; Sargent, C.A.; Jobling, M.A.; Affara, N.; Hurles, M.E. Divergent outcomes of intrachromosomal recombination on the human $\mathrm{Y}$ chromosome: Male infertility and recurrent polymorphism. J. Med. Genet. 2000, 37, 752-758. [CrossRef]

38. Sun, C.; Skaletsky, H.; Rozen, S.; Gromoll, J.; Nieschlag, E.; Oates, R.; Page, D.C. Deletion of azoospermia factor a (AZFa) region of human $\mathrm{Y}$ chromosome caused by recombination between HERV15 proviruses. Hum. Mol. Genet. 2000, 9, 2291-2296. [CrossRef]

39. Kuroda-Kawaguchi, T.; Skaletsky, H.; Brown, L.G.; Minx, P.J.; Cordum, H.S.; Waterston, R.H.; Wilson, R.K.; Silber, S.; Oates, R.; Rozen, S.; et al. The AZFc region of the $\mathrm{Y}$ chromosome features massive palindromes and uniform recurrent deletions in infertile men. Nat. Genet. 2001, 29, 279-286. [CrossRef]

40. Lo Giacco, D.; Chianese, C.; Sanchez-Curbelo, J.; Bassas, L.; Ruiz, P.; Rajmil, O.; Sarquella, J.; Vives, A.; Ruiz-Castañé, E.; Oliva, R.; et al. Clinical relevance of Y-linked CNV screening in male infertility: New insights based on the 8-year experience of a diagnostic genetic laboratory. Eur. J. Hum. Genet. 2014, 22, 754-761. [CrossRef]

41. Ginalski, K.; Rychlewski, L.; Baker, D.; Grishin, N.V. Protein structure prediction for the male-specific region of the human Y chromosome. Proc. Natl. Acad. Sci. USA 2004, 101, 2305-2310. [CrossRef] [PubMed]

42. D'Andrea, A.; Pellman, D. Deubiquitinating enzymes: A new class of biological regulators. Crit. Rev. Biochem. Mol. Biol. 1998, 33, 337-352. [CrossRef] [PubMed]

43. Vogt, P.H.; Falcao, C.L.; Hanstein, R.; Zimmer, J. The AZF proteins. Int. J. Androl. 2008, 31, $383-394$. [CrossRef] [PubMed]

44. Qureshi, S.J.; Ross, A.R.; Ma, K.; Cooke, H.J.; Intyre, M.A.; Chandley, A.C.; Hargreave, T.B. Polymerase chain reaction screening for $\mathrm{Y}$ chromosome microdeletions: A first step towards the diagnosis of genetically-determined spermatogenic failure in men. Mol. Hum. Reprod. 1996, 2, 775-779. [CrossRef] [PubMed]

45. Brown, G.M.; Furlong, R.A.; Sargent, C.A.; Erickson, R.P.; Longepied, G.; Mitchell, M.; Jones, M.H.; Hargreave, T.B.; Cooke, H.J.; Affara, N.A. Characterisation of the coding sequence and fine mapping of the human DFFRY gene and comparative expression analysis and mapping to the Sxrb interval of the mouse $\mathrm{Y}$ chromosome of the Dffry gene. Hum. Mol. Genet. 1998, 7, 97-107. [CrossRef] [PubMed]

46. Krausz, C.; Degl'Innocenti, S.; Nuti, F.; Morelli, A.; Felici, F.; Sansone, M.; Varriale, G.; Forti, G. Natural transmission of USP9Y gene mutations: A new perspective on the role of AZFa genes in male fertility. Hum. Mol. Genet. 2006, 15, 2673-2681. [CrossRef]

47. Nuti, F.; Krausz, C. Gene polymorphisms/mutations relevant to abnormal spermatogenesis. Reprod. Biomed. Online 2008, 16, 504-513. [CrossRef]

48. Tyler-Smith, C.; Krausz, C. The will-o'-the-wisp of genetics-hunting for the azoospermia factor gene. $N$. Engl. J. Med. 2009, 360, 925-927. [CrossRef]

49. Vogt, P.H. Azoospermia factor (AZF) in Yq11: Towards a molecular understanding of its function for human male fertility and spermatogenesis. Reprod. Biomed. Online 2005, 10, 81-93. [CrossRef]

50. Mohr, S.; Stryker, J.M.; Lambowitz, A.M. A DEAD-box protein functions as an ATP-dependent RNA chaperone in group I intron splicing. Cell 2002, 109, 769-779. [CrossRef]

51. Ditton, H.J.; Zimmer, J.; Kamp, C.; Rajpert-De Meyts, E.; Vogt, P.H. The AZFa gene DBY (DDX3Y) is widely transcribed but the protein is limited to the male germ cells by translation control. Hum. Mol. Genet. 2004, 13, 2333-2341. [CrossRef]

52. Jaroszynski, L.; Zimmer, J.; Fietz, D.; Bergmann, M.; Kliesch, S.; Vogt, P.H. Translational control of the AZFa gene DDX3Y by 5'UTR exon-T extension. Int. J. Androl. 2011, 34, 313-326. [CrossRef] 
53. Sekiguchi, T.; Iida, H.; Fukumura, J.; Nishimoto, T. Human DDX3Y, the Y-encoded isoform of RNA helicase DDX3, rescues a hamster temperature-sensitive ET24 mutant cell line with a DDX3X mutation. Exp. Cell Res. 2004, 300, 213-222. [CrossRef] [PubMed]

54. Rauschendorf, M.A.; Zimmer, J.; Ohnmacht, C.; Vogt, P.H. DDX3X, the X homologue of AZFa gene DDX3Y, expresses a complex pattern of transcript variants only in the male germ line. Mol. Hum. Reprod. 2014, 20, 1208-1222. [CrossRef]

55. Lahn, B.T.; Page, D.C. Functional coherence of the human Y chromosome. Science 1997, 278, 675-680. [CrossRef]

56. Mitchell, S.F.; Lorsch, J.R. Should I stay or should I go? Eukaryotic translation initiation factors 1 and $1 \mathrm{~A}$ control start codon recognition. J. Biol. Chem. 2008, 283, 27345-27349. [CrossRef]

57. Kleiman, S.E.; Yogev, L.; Hauser, R.; Botchan, A.; Maymon, B.B.; Paz, G.; Yavetz, H. Expression profile of AZF genes in testicular biopsies of azoospermic men. Hum. Reprod. 2007, 22, 151-158. [CrossRef]

58. Nygard, O.; Nika, H. Identification by RNA-protein cross-linking of ribosomal proteins located at the interface between the small and the large subunits of mammalian ribosomes. EMBO J. 1982, 1, 357-362. [CrossRef]

59. Andres, O.; Kellermann, T.; Lopez-Giraldez, F.; Rozas, J.; Domingo-Roura, X.; Bosch, M. RPS4Y gene family evolution in primates. BMC Evol. Biol. 2008, 8, 142. [CrossRef]

60. Skaletsky, H.; Kuroda-Kawaguchi, T.; Minx, P.J.; Cordum, H.S.; Hillier, L.; Brown, L.G.; Repping, S.; Pyntikova, T.; Ali, J.; Bieri, T.; et al. The male-specific region of the human Y chromosome is a mosaic of discrete sequence classes. Nature 2003, 423, 825-837. [CrossRef]

61. Lopes, A.M.; Miguel, R.N.; Sargent, C.A.; Ellis, P.J.; Amorim, A.; Affara, N.A. The human RPS4 paralogue on Yq11.223 encodes a structurally conserved ribosomal protein and is preferentially expressed during spermatogenesis. BMC Mol. Biol. 2010, 11, 33. [CrossRef]

62. Bernstein, B.E.; Meissner, A.; Lander, E.S. The mammalian epigenome. Cell 2007, 128, 669-681. [CrossRef]

63. Liu, X.; Secombe, J. The Histone Demethylase KDM5 Activates Gene Expression by Recognizing Chromatin Context through Its PHD Reader Motif. Cell Rep. 2015, 13, 2219-2231. [CrossRef]

64. Mizukami, H.; Kim, J.D.; Tabara, S.; Lu, W.; Kwon, C.; Nakashima, M.; Fukamizu, A. KDM5D-mediated H3K4 demethylation is required for sexually dimorphic gene expression in mouse embryonic fibroblasts. J. Biochem. 2019, 165, 335-342. [CrossRef]

65. Blair, L.P.; Cao, J.; Zou, M.R.; Sayegh, J.; Yan, Q. Epigenetic Regulation by Lysine Demethylase 5 (KDM5) Enzymes in Cancer. Cancers 2011, 3, 1383-1404. [CrossRef]

66. Akimoto, C.; Kitagawa, H.; Matsumoto, T.; Kato, S. Spermatogenesis-specific association of SMCY and MSH5. Genes Cells Devoted Mol. Cell. Mech. 2008, 13, 623-633. [CrossRef]

67. Navarro-Costa, P.; Plancha, C.E.; Goncalves, J. Genetic dissection of the AZF regions of the human Y chromosome: Thriller or filler for male (in)fertility? J. Biomed. Biotechnol. 2010, 2010, 936569. [CrossRef]

68. Bhowmick, B.K.; Satta, Y.; Takahata, N. The origin and evolution of human ampliconic gene families and ampliconic structure. Genome Res. 2007, 17, 441-450. [CrossRef]

69. Repping, S.; van Daalen, S.K.; Brown, L.G.; Korver, C.M.; Lange, J.; Marszalek, J.D.; Pyntikova, T.; van der Veen, F.; Skaletsky, H.; Page, D.C.; et al. High mutation rates have driven extensive structural polymorphism among human Y chromosomes. Nat. Genet. 2006, 38, 463-467. [CrossRef]

70. Page, D.C. 2003 Curt Stern Award address. On low expectation exceeded; or, the genomic salvation of the $Y$ chromosome. Am. J. Hum. Genet. 2004, 74, 399-402. [CrossRef]

71. Seboun, E.; Barbaux, S.; Bourgeron, T.; Nishi, S.; Agulnik, A.; Egashira, M.; Nikkawa, N.; Bishop, C.; Fellous, M.; McElreavey, K.; et al. Gene sequence, localization, and evolutionary conservation of DAZLA, a candidate male sterility gene. Genomics 1997, 41, 227-235. [CrossRef]

72. Saxena, R.; de Vries, J.W.; Repping, S.; Alagappan, R.K.; Skaletsky, H.; Brown, L.G.; Ma, P.; Chen, E.; Hoovers, J.M.; Page, D.C. Four DAZ genes in two clusters found in the AZFc region of the human Y chromosome. Genomics 2000, 67, 256-267. [CrossRef]

73. Kato, Y.; Katsuki, T.; Kokubo, H.; Masuda, A.; Saga, Y. Dazl is a target RNA suppressed by mammalian NANOS2 in sexually differentiating male germ cells. Nat. Commun. 2016, 7, 11272. [CrossRef]

74. Ruggiu, M.; Speed, R.; Taggart, M.; McKay, S.J.; Kilanowski, F.; Saunders, P.; Dorin, J.; Cooke, H.J. The mouse Dazla gene encodes a cytoplasmic protein essential for gametogenesis. Nature 1997, 389, 73-77. [CrossRef] 
75. Oud, M.S.; Volozonoka, L.; Smits, R.M.; Vissers, L.; Ramos, L.; Veltman, J.A. A systematic review and standardized clinical validity assessment of male infertility genes. Hum. Reprod. 2019, 34, 932-941. [CrossRef]

76. Tuttelmann, F.; Ruckert, C.; Ropke, A. Disorders of spermatogenesis: Perspectives for novel genetic diagnostics after 20 years of unchanged routine. Med. Genet. 2018, 30, 12-20. [CrossRef]

77. Callewaert, L.; Christiaens, V.; Haelens, A.; Verrijdt, G.; Verhoeven, G.; Claessens, F. Implications of a polyglutamine tract in the function of the human androgen receptor. Biochem. Biophys. Res. Commun. 2003, 306, 46-52. [CrossRef]

78. Roy, A.K.; Lavrovsky, Y.; Song, C.S.; Chen, S.; Jung, M.H.; Velu, N.K.; Bi, B.Y.; Chatterjee, B. Regulation of androgen action. Vitam. Horm. 1999, 55, 309-352.

79. McLachlan, R.I.; Wreford, N.G.; O'Donnell, L.; de Kretser, D.M.; Robertson, D.M. The endocrine regulation of spermatogenesis: Independent roles for testosterone and FSH. J. Endocrinol. 1996, 148, 1-9. [CrossRef]

80. Gottlieb, B.; Beitel, L.K.; Nadarajah, A.; Paliouras, M.; Trifiro, M. The androgen receptor gene mutations database: 2012 update. Hum. Mutat. 2012, 33, 887-894. [CrossRef]

81. Yeh, S.; Tsai, M.Y.; Xu, Q.; Mu, X.M.; Lardy, H.; Huang, K.E.; Lin, H.; Yeh, S.D.; Altuwaijri, S.; Zhou, X.; et al. Generation and characterization of androgen receptor knockout (ARKO) mice: An in vivo model for the study of androgen functions in selective tissues. Proc. Natl. Acad. Sci. USA 2002, 99, 13498-13503. [CrossRef]

82. De Gendt, K.; Swinnen, J.V.; Saunders, P.T.; Schoonjans, L.; Dewerchin, M.; Devos, A.; Tan, K.; Atanassova, N.; Claessens, F.; Lécureuil, C.; et al. A Sertoli cell-selective knockout of the androgen receptor causes spermatogenic arrest in meiosis. Proc. Natl. Acad. Sci. USA 2004, 101, 1327-1332. [CrossRef]

83. Edwards, A.; Hammond, H.A.; Jin, L.; Caskey, C.T.; Chakraborty, R. Genetic variation at five trimeric and tetrameric tandem repeat loci in four human population groups. Genomics 1992, 12, 241-253. [CrossRef]

84. Tut, T.G.; Ghadessy, F.J.; Trifiro, M.A.; Pinsky, L.; Yong, E.L. Long polyglutamine tracts in the androgen receptor are associated with reduced trans-activation, impaired sperm production, and male infertility. J. Clin. Endocrinol. Metab. 1997, 82, 3777-3782. [CrossRef]

85. Krausz, C.; Escamilla, A.R.; Chianese, C. Genetics of male infertility: From research to clinic. Reproduction 2015, 150, R159-R174. [CrossRef]

86. Davis-Dao, C.A.; Tuazon, E.D.; Sokol, R.Z.; Cortessis, V.K. Male infertility and variation in CAG repeat length in the androgen receptor gene: A meta-analysis. J. Clin. Endocrinol. Metab. 2007, 92, 4319-4326. [CrossRef]

87. Westerveld, H.; Visser, L.; Tanck, M.; van der Veen, F.; Repping, S. CAG repeat length variation in the androgen receptor gene is not associated with spermatogenic failure. Fertil. Steril. 2008, 89, $253-259$. [CrossRef]

88. Mangelsdorf, D.J.; Thummel, C.; Beato, M.; Herrlich, P.; Schutz, G.; Umesono, K.; Blumberg, B.; Kastner, P.; Mark, M.; Chambon, P.; et al. The nuclear receptor superfamily: The second decade. Cell 1995, 83, 835-839. [CrossRef]

89. Ikeda, Y.; Lala, D.S.; Luo, X.; Kim, E.; Moisan, M.P.; Parker, K.L. Characterization of the mouse FTZ-F1 gene, which encodes a key regulator of steroid hydroxylase gene expression. Mol. Endocrinol. 1993, 7, 852-860.

90. Morohashi, K.; Iida, H.; Nomura, M.; Hatano, O.; Honda, S.; Tsukiyama, T.; Niwa, O.; Hara, T.; Takakusu, A.; Shibata, Y.; et al. Functional difference between Ad4BP and ELP, and their distributions in steroidogenic tissues. Mol. Endocrinol. 1994, 8, 643-653.

91. Barnhart, K.M.; Mellon, P.L. The orphan nuclear receptor, steroidogenic factor-1, regulates the glycoprotein hormone alpha-subunit gene in pituitary gonadotropes. Mol. Endocrinol. 1994, 8, 878-885. [PubMed]

92. Ingraham, H.A.; Lala, D.S.; Ikeda, Y.; Luo, X.; Shen, W.H.; Nachtigal, M.W.; Abbud, R.; Nilson, J.H.; Parker, K.L. The nuclear receptor steroidogenic factor 1 acts at multiple levels of the reproductive axis. Genes Dev. 1994, 8, 2302-2312. [CrossRef] [PubMed]

93. Shinoda, K.; Lei, H.; Yoshii, H.; Nomura, M.; Nagano, M.; Shiba, H.; Sasaki, H.; Osawa, Y.; Ninomiya, Y.; Niwa, O.; et al. Developmental defects of the ventromedial hypothalamic nucleus and pituitary gonadotroph in the Ftz-F1 disrupted mice. Dev. Dyn. 1995, 204, 22-29. [CrossRef]

94. Luo, X.; Ikeda, Y.; Parker, K.L. A cell-specific nuclear receptor is essential for adrenal and gonadal development and sexual differentiation. Cell 1994, 77, 481-490. [CrossRef]

95. Jameson, J.L. Of mice and men: The tale of steroidogenic factor-1. J. Clin. Endocrinol. Metab. 2004, 89, 5927-5929. [CrossRef] 
96. Sadovsky, Y.; Crawford, P.A.; Woodson, K.G.; Polish, J.A.; Clements, M.A.; Tourtellotte, L.M.; Simburger, K.; Milbrandt, J. Mice deficient in the orphan receptor steroidogenic factor 1 lack adrenal glands and gonads but express P450 side-chain-cleavage enzyme in the placenta and have normal embryonic serum levels of corticosteroids. Proc. Natl. Acad. Sci. USA 1995, 92, 10939-10943. [CrossRef]

97. Ferraz-de-Souza, B.; Lin, L.; Achermann, J.C. Steroidogenic factor-1 (SF-1, NR5A1) and human disease. Mol. Cell. Endocrinol. 2011, 336, 198-205. [CrossRef]

98. Bashamboo, A.; Ferraz-de-Souza, B.; Lourenco, D.; Lin, L.; Sebire, N.J.; Montjean, D.; Bignon-Topalovic, J.; Mandelbaum, J.; Siffroi, J.P.; Christin-Maitre, S.; et al. Human male infertility associated with mutations in NR5A1 encoding steroidogenic factor 1. Am. J. Hum. Genet. 2010, 87, 505-512. [CrossRef]

99. Ropke, A.; Tewes, A.C.; Gromoll, J.; Kliesch, S.; Wieacker, P.; Tuttelmann, F. Comprehensive sequence analysis of the NR5A1 gene encoding steroidogenic factor 1 in a large group of infertile males. Eur. J. Hum. Genet. 2013, 21, 1012-1015. [CrossRef]

100. Ferlin, A.; Rocca, M.S.; Vinanzi, C.; Ghezzi, M.; Di Nisio, A.; Foresta, C. Mutational screening of NR5A1 gene encoding steroidogenic factor 1 in cryptorchidism and male factor infertility and functional analysis of seven undescribed mutations. Fertil. Steril. 2015, 104, 163-169.e161. [CrossRef] [PubMed]

101. Zare-Abdollahi, D.; Safari, S.; Mirfakhraie, R.; Movafagh, A.; Bastami, M.; Azimzadeh, P.; Salsabili, N.; Ebrahimizadeh, W.; Salami, S.; Omrani, M.D. Mutational screening of the NR5A1 in azoospermia. Andrologia 2015, 47, 395-401. [CrossRef] [PubMed]

102. Sudhakar, D.V.S.; Nizamuddin, S.; Manisha, G.; Devi, J.R.; Gupta, N.J.; Chakravarthy, B.N.; Deenadayal, M.; Singh, L.; Thangaraj, K. NR5A1 mutations are not associated with male infertility in Indian men. Andrologia 2018, 50. [CrossRef] [PubMed]

103. Raymond, C.S.; Shamu, C.E.; Shen, M.M.; Seifert, K.J.; Hirsch, B.; Hodgkin, J.; Zarkower, D. Evidence for evolutionary conservation of sex-determining genes. Nature 1998, 391, 691-695. [CrossRef] [PubMed]

104. Volff, J.N.; Zarkower, D.; Bardwell, V.J.; Schartl, M. Evolutionary dynamics of the DM domain gene family in metazoans. J. Mol. Evol. 2003, 57 (Suppl. 1), S241-S249. [CrossRef]

105. Zarkower, D. Establishing sexual dimorphism: Conservation amidst diversity? Nat. Rev. Genet. 2001, 2, 175-185. [CrossRef]

106. Moniot, B.; Berta, P.; Scherer, G.; Sudbeck, P.; Poulat, F. Male specific expression suggests role of DMRT1 in human sex determination. Mech. Dev. 2000, 91, 323-325. [CrossRef]

107. Huang, S.; Ye, L.; Chen, H. Sex determination and maintenance: The role of DMRT1 and FOXL2. Asian J. Androl. 2017, 19, 619-624.

108. Raymond, C.S.; Murphy, M.W.; O’Sullivan, M.G.; Bardwell, V.J.; Zarkower, D. Dmrt1, a gene related to worm and fly sexual regulators, is required for mammalian testis differentiation. Genes Dev. 2000, 14, 2587-2595. [CrossRef]

109. Lopes, A.M.; Aston, K.I.; Thompson, E.; Carvalho, F.; Goncalves, J.; Huang, N.; Matthiesen, R.; Noordam, M.J.; Quintela, I.; Ramu, A.; et al. Human spermatogenic failure purges deleterious mutation load from the autosomes and both sex chromosomes, including the gene DMRT1. PLoS Genet. 2013, 9, e1003349. [CrossRef]

110. Tewes, A.C.; Ledig, S.; Tuttelmann, F.; Kliesch, S.; Wieacker, P. DMRT1 mutations are rarely associated with male infertility. Fertil. Steril. 2014, 102, 816-820.e813. [CrossRef]

111. Araujo, T.F.; Friedrich, C.; Grangeiro, C.H.P.; Martelli, L.R.; Grzesiuk, J.D.; Emich, J.; Wyrwoll, M.J.; Kliesch, S.; Simões, A.L.; Tüttelmann, F.; et al. Sequence analysis of 37 candidate genes for male infertility: Challenges in variant assessment and validating genes. Andrology 2019, in press. [CrossRef] [PubMed]

112. Lima, A.C.; Carvalho, F.; Goncalves, J.; Fernandes, S.; Marques, P.I.; Sousa, M.; Barros, A.; Seixas, S.; Amorim, A.; Conrad, D.F.; et al. Rare double sex and mab-3-related transcription factor 1 regulatory variants in severe spermatogenic failure. Andrology 2015, 3, 825-833. [CrossRef] [PubMed]

113. Wang, P.J.; McCarrey, J.R.; Yang, F.; Page, D.C. An abundance of X-linked genes expressed in spermatogonia. Nat. Genet. 2001, 27, 422-426. [CrossRef] [PubMed]

114. Adelman, C.A.; Petrini, J.H. ZIP4H (TEX11) deficiency in the mouse impairs meiotic double strand break repair and the regulation of crossing over. PLoS Genet. 2008, 4, e1000042. [CrossRef] [PubMed]

115. Yatsenko, A.N.; Georgiadis, A.P.; Ropke, A.; Berman, A.J.; Jaffe, T.; Olszewska, M.; Westernströer, B.; Sanfilippo, J.; Kurpisz, M.; Rajkovic, A.; et al. X-linked TEX11 mutations, meiotic arrest, and azoospermia in infertile men. N. Engl. J. Med. 2015, 372, 2097-2107. [CrossRef] 
116. Yang, F.; Silber, S.; Leu, N.A.; Oates, R.D.; Marszalek, J.D.; Skaletsky, H.; Brown, L.G.; Rozen, S.; Page, D.C.; Wang, P.J. TEX11 is mutated in infertile men with azoospermia and regulates genome-wide recombination rates in mouse. EMBO Mol. Med. 2015, 7, 1198-1210. [CrossRef]

117. Nakamura, S.; Miyado, M.; Saito, K.; Katsumi, M.; Nakamura, A.; Kobori, Y.; Tanaka, Y.; Ishikawa, H.; Yoshida, A.; Okada, H.; et al. Next-generation sequencing for patients with non-obstructive azoospermia: Implications for significant roles of monogenic/oligogenic mutations. Andrology 2017, 5, 824-831. [CrossRef]

118. Ben Khelifa, M.; Ghieh, F.; Boudjenah, R.; Hue, C.; Fauvert, D.; Dard, R.; Garchon, H.J.; Vialard, F.; et al. A MEI1 homozygous missense mutation associated with meiotic arrest in a consanguineous family. Hum. Reprod. 2018, 33, 1034-1037. [CrossRef]

119. Sha, Y.; Zheng, L.; Ji, Z.; Mei, L.; Ding, L.; Lin, S.; Wang, X.; Yang, X.; Li, P. A novel TEX11 mutation induces azoospermia: A case report of infertile brothers and literature review. BMC Med. Genet. 2018, $19,63$. [CrossRef]

120. Boroujeni, P.B.; Sabbaghian, M.; Totonchi, M.; Sodeifi, N.; Sarkardeh, H.; Samadian, A.; Sadighi-Gilani, M.A.; Gourabi, H. Expression analysis of genes encoding TEX11, TEX12, TEX14 and TEX15 in testis tissues of men with non-obstructive azoospermia. JBRA Assist. Reprod. 2018, 22, 185-192. [CrossRef]

121. Greenbaum, M.P.; Yan, W.; Wu, M.H.; Lin, Y.N.; Agno, J.E.; Sharma, M.; Braun, R.E.; Rajkovic, A.; Matzuk, M.M. TEX14 is essential for intercellular bridges and fertility in male mice. Proc. Natl. Acad. Sci. USA 2006, 103, 4982-4987. [CrossRef] [PubMed]

122. Kim, H.J.; Yoon, J.; Matsuura, A.; Na, J.H.; Lee, W.K.; Kim, H.; Choi, J.W.; Park, J.E.; Park, S.J.; Kim, K.T.; et al. Structural and biochemical insights into the role of testis-expressed gene 14 (TEX14) in forming the stable intercellular bridges of germ cells. Proc. Natl. Acad. Sci. USA 2015, 112, 12372-12377. [CrossRef] [PubMed]

123. Fakhro, K.A.; Elbardisi, H.; Arafa, M.; Robay, A.; Rodriguez-Flores, J.L.; Al-Shakaki, A.; Syed, N.; Mezey, J.G.; Abi Khalil, C.; Malek, J.A.; et al. Point-of-care whole-exome sequencing of idiopathic male infertility. Genet. Med. 2018, 20, 1365-1373. [CrossRef]

124. Yang, F.; Eckardt, S.; Leu, N.A.; McLaughlin, K.J.; Wang, P.J. Mouse TEX15 is essential for DNA double-strand break repair and chromosomal synapsis during male meiosis. J. Cell Biol. 2008, 180, 673-679. [CrossRef]

125. Gershoni, M.; Hauser, R.; Yogev, L.; Lehavi, O.; Azem, F.; Yavetz, H.; Pietrokovski, S.; Kleiman, S.E. A familial study of azoospermic men identifies three novel causative mutations in three new human azoospermia genes. Genet. Med. 2017, 19, 998-1006. [CrossRef]

126. Okutman, O.; Muller, J.; Baert, Y.; Serdarogullari, M.; Gultomruk, M.; Piton, A.; Rombaut, C.; Benkhalifa, M.; Teletin, M.; Skory, V.; et al. Exome sequencing reveals a nonsense mutation in TEX15 causing spermatogenic failure in a Turkish family. Hum. Mol. Genet. 2015, 24, 5581-5588. [CrossRef]

127. Colombo, R.; Pontoglio, A.; Bini, M. Two Novel TEX15 Mutations in a Family with Nonobstructive Azoospermia. Gynecol. Obstet. Investig. 2017, 82, 283-286. [CrossRef]

128. Zhou, Y.D.; Barnard, M.; Tian, H.; Li, X.; Ring, H.Z.; Francke, U.; Shelton, J.; Richardson, J.; Russell, D.W.; McKnight, S.L. Molecular characterization of two mammalian bHLH-PAS domain proteins selectively expressed in the central nervous system. Proc. Natl. Acad. Sci. USA 1997, 94, 713-718. [CrossRef]

129. Reick, M.; Garcia, J.A.; Dudley, C.; McKnight, S.L. NPAS2: An analog of clock operative in the mammalian forebrain. Science 2001, 293, 506-509. [CrossRef]

130. Ramasamy, R.; Bakircioglu, M.E.; Cengiz, C.; Karaca, E.; Scovell, J.; Jhangiani, S.N.; Akdemir, Z.C.; Bainbridge, M.; Yu, Y.; Huff, C.; et al. Whole-exome sequencing identifies novel homozygous mutation in NPAS2 in family with nonobstructive azoospermia. Fertil. Steril. 2015, 104, 286-291. [CrossRef]

131. Choi, Y.; Jeon, S.; Choi, M.; Lee, M.H.; Park, M.; Lee, D.R.; Jun, K.Y.; Kwon, Y.; Lee, O.H.; Song, S.H.; et al. Mutations in SOHLH1 gene associate with nonobstructive azoospermia. Hum. Mutat. 2010, 31, 788-793. [CrossRef]

132. Stouffs, K.; Lissens, W.; Tournaye, H.; Van Steirteghem, A.; Liebaers, I. Possible role of USP26 in patients with severely impaired spermatogenesis. Eur. J. Hum. Genet. 2005, 13, 336-340. [CrossRef]

133. Ma, Q.; Li, Y.; Guo, H.; Li, C.; Chen, J.; Luo, M.; Jiang, Z.; Li, H.; Gui, Y. A Novel Missense Mutation in USP26 Gene Is Associated With Nonobstructive Azoospermia. Reprod. Sci 2016, 23, 1434-1441. [CrossRef]

134. Miyamoto, T.; Hasuike, S.; Yogev, L.; Maduro, M.R.; Ishikawa, M.; Westphal, H.; Lamb, D.J. Azoospermia in patients heterozygous for a mutation in SYCP3. Lancet 2003, 362, 1714-1719. [CrossRef]

135. Ayhan, O.; Balkan, M.; Guven, A.; Hazan, R.; Atar, M.; Tok, A.; Tolun, A. Truncating mutations in TAF4B and ZMYND15 causing recessive azoospermia. J. Med. Genet. 2014, 51, 239-244. [CrossRef] 
136. Maor-Sagie, E.; Cinnamon, Y.; Yaacov, B.; Shaag, A.; Goldsmidt, H.; Zenvirt, S.; Laufer, N.; Richler, C.; Frumkin, A. Deleterious mutation in SYCE1 is associated with non-obstructive azoospermia. J. Assist. Reprod. Genet. 2015, 32, 887-891. [CrossRef]

137. Tenenbaum-Rakover, Y.; Weinberg-Shukron, A.; Renbaum, P.; Lobel, O.; Eideh, H.; Gulsuner, S.; Dahary, D.; Abu-Rayyan, A.; Kanaan, M.; Levy-Lahad, E.; et al. Minichromosome maintenance complex component 8 (MCM8) gene mutations result in primary gonadal failure. J. Med. Genet. 2015, 52, 391-399. [CrossRef]

138. Mou, L.; Wang, Y.; Li, H.; Huang, Y.; Jiang, T.; Huang, W.; Li, Z.; Chen, J.; Xie, J.; Liu, Y.; et al. A dominant-negative mutation of HSF2 associated with idiopathic azoospermia. Hum. Genet. 2013, 132, 159-165. [CrossRef]

139. Kherraf, Z.E.; Christou-Kent, M.; Karaouzene, T.; Amiri-Yekta, A.; Martinez, G.; Vargas, A.S.; Lambert, E.; Borel, C.; Dorphin, B.; Aknin-Seifer, I.; et al. SPINK2 deficiency causes infertility by inducing sperm defects in heterozygotes and azoospermia in homozygotes. EMBO Mol. Med. 2017, 9, 1132-1149. [CrossRef]

140. Arafat, M.; Har-Vardi, I.; Harlev, A.; Levitas, E.; Zeadna, A.; Abofoul-Azab, M.; Dyomin, V.; Sheffield, V.C.; Lunenfeld, E.; Huleihel, M.; et al. Mutation in TDRD9 causes non-obstructive azoospermia in infertile men. J. Med. Genet. 2017, 54, 633-639. [CrossRef]

141. Krausz, C. Male infertility: Pathogenesis and clinical diagnosis. Best Pract. Res. Clin. Endocrinol. Metab. 2011, 25, 271-285. [CrossRef] [PubMed]

142. Tuttelmann, F.; Rajpert-De Meyts, E.; Nieschlag, E.; Simoni, M. Gene polymorphisms and male infertility-a meta-analysis and literature review. Reprod. Biomed. Online 2007, 15, 643-658. [CrossRef]

143. Mobasseri, N.; Babaei, F.; Karimian, M.; Nikzad, H. Androgen receptor (AR)-CAG trinucleotide repeat length and idiopathic male infertility: A case-control trial and a meta-analysis. EXCLI J. 2018, 17, 1167-1179. [PubMed]

144. Pan, B.; Li, R.; Chen, Y.; Tang, Q.; Wu, W.; Chen, L.; Lu, C.; Pan, F.; Ding, H.; Xia, Y.; et al. Genetic Association between Androgen Receptor Gene CAG Repeat Length Polymorphism and Male Infertility: A Meta-Analysis. Medicine 2016, 95, e2878. [CrossRef]

145. Munoz, X.; Navarro, M.; Mata, A.; Bassas, L.; Larriba, S. Association of PIWIL4 genetic variants with germ cell maturation arrest in infertile Spanish men. Asian J. Androl. 2014, 16, 931-933.

146. Kamaliyan, Z.; Pouriamanesh, S.; Amin-Beidokhti, M.; Rezagholizadeh, A.; Mirfakhraie, R. HIWI2 rs508485 Polymorphism is Associated with Non-obstructive Azoospermia in Iranian Patients. Rep. Biochem. Mol. Biol. 2017, 5, 108-111.

147. Kamaliyan, Z.; Pouriamanesh, S.; Soosanabadi, M.; Gholami, M.; Mirfakhraie, R. Investigation of piwi-interacting RNA pathway genes role in idiopathic non-obstructive azoospermia. Sci. Rep. 2018, 8, 142. [CrossRef]

148. Stuppia, L.; Gatta, V.; Scarciolla, O.; Colosimo, A.; Guanciali-Franchi, P.; Calabrese, G.; Palka, G. The methylenetethrahydrofolate reductase (MTHFR) C677T polymorphism and male infertility in Italy. J. Endocrinol. Investig. 2003, 26, 620-622. [CrossRef]

149. Gava, M.M.; Kayaki, E.A.; Bianco, B.; Teles, J.S.; Christofolini, D.M.; Pompeo, A.C.; Glina, S.; Barbosa, C.P. Polymorphisms in folate-related enzyme genes in idiopathic infertile Brazilian men. Reprod. Sci. 2011, 18, 1267-1272. [CrossRef]

150. Kim, S.Y.; Lim, J.W.; Kim, J.W.; Park, S.Y.; Seo, J.T. Association between genetic polymorphisms in folate-related enzyme genes and infertile men with non-obstructive azoospermia. Syst. Biol. Reprod. Med. 2015, 61, 286-292.

151. Lee, H.C.; Jeong, Y.M.; Lee, S.H.; Cha, K.Y.; Song, S.H.; Kim, N.K.; Lee, K.W.; Lee, S. Association study of four polymorphisms in three folate-related enzyme genes with non-obstructive male infertility. Hum. Reprod. 2006, 21, 3162-3170. [CrossRef] [PubMed]

152. Ying, H.Q.; Pu, X.Y.; Liu, S.R.; A, Z.-C. Genetic variants of eNOS gene may modify the susceptibility to idiopathic male infertility. Biomarkers 2013, 18, 412-417. [CrossRef] [PubMed]

153. Chang, J.; Pan, F.; Tang, Q.; Wu, W.; Chen, M.; Lu, C.; Ding, H.; Hu, L.; Chen, D.; Xia, Y.; et al. eNOS gene T786C, G894T and 4a4b polymorphisms and male infertility susceptibility: A meta-analysis. Andrologia 2017, 49. [CrossRef]

154. Ying, H.Q.; Scott, M.B.; Zhou-Cun, A. Relationship of SNP of H2BFWT gene to male infertility in a Chinese population with idiopathic spermatogenesis impairment. Biomarkers 2012, 17, 402-406. [CrossRef] 
155. Rafatmanesh, A.; Nikzad, H.; Ebrahimi, A.; Karimian, M.; Zamani, T. Association of the c. $-9 \mathrm{C}>\mathrm{T}$ and c.368A $>$ G transitions in H2BFWT gene with male infertility in an Iranian population. Andrologia 2018, 50. [CrossRef]

156. Haji Ebrahim Zargar, H.; Mohseni Meybodi, A.; Sabbaghian, M.; Shahhoseini, M.; Asadpor, U.; Sadighi Gilani, M.A.; Chehrazi, M.; Farhangniya, M.; Shahzadeh Fazeli, S.A. Association of Two Polymorphisms in H2B.W Gene with Azoospermia and Severe Oligozoospermia in An Iranian Population. Int. J. Fertil. Steril. 2015, 9, 205-214.

157. Yoshida, K.I.; Yano, M.; Chiba, K.; Honda, M.; Kitahara, S. CAG repeat length in the androgen receptor gene is enhanced in patients with idiopathic azoospermia. Urology 1999, 54, 1078-1081. [CrossRef]

158. Sato, H.; Miyamoto, T.; Yogev, L.; Namiki, M.; Koh, E.; Hayashi, H.; Sasaki, Y.; Ishikawa, M.; Lamb, D.J.; Matsumoto, N.; et al. Polymorphic alleles of the human MEI1 gene are associated with human azoospermia by meiotic arrest. J. Hum. Genet. 2006, 51, 533-540. [CrossRef]

159. Wilson, G.R.; Sim, M.L.; Brody, K.M.; Taylor, J.M.; McLachlan, R.I.; O’Bryan, M.K.; Delatycki, M.B.; Lockhart, P.J. Molecular analysis of the PArkin co-regulated gene and association with male infertility. Fertil. Steril. 2010, 93, 2262-2268. [CrossRef]

160. Ma, J.; Lu, H.Y.; Xia, Y.K.; Dong, H.B.; Gu, A.H.; Li, Z.Y.; Li, Z.; Chen, A.M.; Wang, X.R.; Wang, S.L. BCL2 Ala43Thr is a functional variant associated with protection against azoospermia in a Han-Chinese population. Biol. Reprod. 2010, 83, 656-662. [CrossRef]

161. Aston, K.I.; Krausz, C.; Laface, I.; Ruiz-Castane, E.; Carrell, D.T. Evaluation of 172 candidate polymorphisms for association with oligozoospermia or azoospermia in a large cohort of men of European descent. Hum. Reprod. 2010, 25, 1383-1397. [CrossRef]

162. Hu, Z.; Xia, Y.; Guo, X.; Dai, J.; Li, H.; Hu, H.; Jiang, Y.; Lu, F.; Wu, Y.; Yang, X.; et al. A genome-wide association study in Chinese men identifies three risk loci for non-obstructive azoospermia. Nat. Genet. 2011, 44, 183-186. [CrossRef] [PubMed]

163. Zhao, H.; Xu, J.; Zhang, H.; Sun, J.; Sun, Y.; Wang, Z.; Liu, J.; Ding, Q.; Lu, S.; Shi, R.; et al. A genome-wide association study reveals that variants within the HLA region are associated with risk for nonobstructive azoospermia. Am. J. Hum. Genet. 2012, 90, 900-906. [CrossRef] [PubMed]

164. Li, Z.; Yu, J.; Zhang, T.; Li, H.; Ni, Y. rs189037, a functional variant in ATM gene promoter, is associated with idiopathic nonobstructive azoospermia. Fertil. Steril. 2013, 100, 1536-1541.e1531. [CrossRef] [PubMed]

165. Hu, Z.; Li, Z.; Yu, J.; Tong, C.; Lin, Y.; Guo, X.; Lu, F.; Dong, J.; Xia, Y.; Wen, Y.; et al. Association analysis identifies new risk loci for non-obstructive azoospermia in Chinese men. Nat. Commun. 2014, 5, 3857. [CrossRef]

166. Qin, Y.; Ji, J.; Du, G.; Wu, W.; Dai, J.; Hu, Z.; Sha, J.; Hang, B.; Lu, C.; Xia, Y.; et al. Comprehensive pathway-based analysis identifies associations of BCL2, GNAO1 and CHD2 with non-obstructive azoospermia risk. Hum. Reprod. 2014, 29, 860-866. [CrossRef]

167. Ni, B.; Ma, H.; Lin, Y.; Dai, J.; Guo, X.; Xia, Y.; Sha, J.; Hu, Z. Genetic variants in Ser-Arg protein-coding genes are associated with the risk of nonobstructive azoospermia in Chinese men. Fertil. Steril. 2014, 101, 1711-7 e1-1711-7 e2. [CrossRef]

168. Ghalkhani, E.; Sheidai, M.; Gourabi, H.; Noormohammadi, Z.; Bakhtari, N.; Malekasgar, A.M. Study of single nucleotide polymorphism (rs28368082) in SPO11 gene and its association with male infertility. J. Assist. Reprod. Genet. 2014, 31, 1205-1210. [CrossRef]

169. Xiong, D.K.; Chen, H.H.; Ding, X.P.; Zhang, S.H.; Zhang, J.H. Association of polymorphisms in glutathione S-transferase genes (GSTM1, GSTT1, GSTP1) with idiopathic azoospermia or oligospermia in Sichuan, China. Asian J. Androl. 2015, 17, 481-486. [CrossRef]

170. Zhang, Y.; He, X.J.; Song, B.; Ye, L.; Xie, X.S.; Ruan, J.; Zhou, F.S.; Zuo, X.B.; Cao, Y.X.; Du, W.D. Association of single nucleotide polymorphisms in the USF1, GTF2A1L and OR2W3 genes with non-obstructive azoospermia in the Chinese population. J. Assist. Reprod. Genet. 2015, 32, 95-101. [CrossRef]

171. Sato, Y.; Tajima, A.; Tsunematsu, K.; Nozawa, S.; Yoshiike, M.; Koh, E.; Kanaya, J.; Namiki, M.; Matsumiya, K.; Tsujimura, A.; et al. An association study of four candidate loci for human male fertility traits with male infertility. Hum. Reprod. 2015, 30, 1510-1514. [CrossRef] [PubMed]

172. Gharesi-Fard, B.; Ghasemi, Z.; Shakeri, S.; Behdin, S.; Aghaei, F.; Malek-Hosseini, Z. The frequency of follicle stimulating hormone receptor gene polymorphisms in Iranian infertile men with azoospermia. Iran. J. Reprod. Med. 2015, 13, 673-678. [PubMed] 
173. Zhang, X.; Ding, M.; Ding, X.; Li, T.; Chen, H. Six polymorphisms in genes involved in DNA double-strand break repair and chromosome synapsis: Association with male infertility. Syst. Biol. Reprod. Med. 2015, 61, 187-193. [CrossRef] [PubMed]

174. Zhang, W.; Lin, W.Q.; Cao, H.F.; Li, C.Y.; Li, F. Association of a miR-34b binding site single nucleotide polymorphism in the 3 -untranslated region of the methylenetetrahydrofolate reductase gene with susceptibility to male infertility. Genet. Mol. Res. 2015, 14, 12196-12204. [CrossRef] [PubMed]

175. Song, B.; Zhang, Y.; He, X.J.; Du, W.D.; Ruan, J.; Zhou, F.S.; Wu, H.; Zha, X.; Xie, X.S.; Ye, L.; et al. Association of genetic variants in SOHLH1 and SOHLH2 with non-obstructive azoospermia risk in the Chinese population. Eur. J. Obstet. Gynecol. Reprod. Biol. 2015, 184, 48-52. [CrossRef]

176. Lu, J.; Gu, H.; Tang, Q.; Wu, W.; Yuan, B.; Guo, D.; Wei, Y.; Sun, H.; Xia, Y.; Ding, H.; et al. Common SNP in hsa-miR-196a-2 increases hsa-miR-196a-5p expression and predisposes to idiopathic male infertility in Chinese Han population. Sci. Rep. 2016, 6, 19825. [CrossRef]

177. Chihara, M.; Yoshihara, K.; Ishiguro, T.; Adachi, S.; Okada, H.; Kashima, K.; Sato, T.; Tanaka, A.; Tanaka, K.; Enomoto, T. Association of NR3C1/Glucocorticoid Receptor gene SNP with azoospermia in Japanese men. J. Obstet. Gynaecol. Res. 2016, 42, 59-66. [CrossRef]

178. Zhu, X.; Liu, Z.; Zhang, M.; Gong, R.; Xu, Y.; Wang, B. Association of the methylenetetrahydrofolate reductase gene C677T polymorphism with the risk of male infertility: A meta-analysis. Ren. Fail. 2016, 38, 185-193. [CrossRef]

179. Najafipour, R.; Rashvand, Z.; Alizadeh, A.; Aleyasin, A.; Moghbelinejad, S. Association of G/T(rs222859) polymorphism in Exon 1 of YBX2 gene with azoospermia, among Iranian infertile males. Andrologia 2016, 48, 956-960. [CrossRef]

180. Ramgir, S.S.; Sekar, N.; Jindam, D.; Abilash, V.G. Association of CYP1A1²A Polymorphism with Idiopathic Non-Obstructive Azoospermia in A South Indian Cohort. Int. J. Fertil. Steril. 2017, 11, 142-147.

181. Asgari, R.; Mansouri, K.; Bakhtiari, M.; Bidmeshkipour, A.; Yari, K.; Shaveisi-Zadeh, F.; Vaisi-Raygani, A. Association of FAS-670A/G and FASL-844C/T polymorphisms with idiopathic azoospermia in Western Iran. Eur. J. Obstet. Gynecol. Reprod. Biol. 2017, 218, 55-59. [CrossRef] [PubMed]

182. Jahantigh, D.; Hosseinzadeh Colagar, A. XRCC5 VNTR, XRCC6 -61C>G, and XRCC7 6721G>T Gene Polymorphisms Associated with Male Infertility Risk: Evidences from Case-Control and In Silico Studies. Int. J. Endocrinol. 2017, 2017, 4795076. [CrossRef] [PubMed]

183. Ashrafzadeh, H.R.; Nazari, T.; Dehghan Tezerjani, M.; Khademi Bami, M.; Ghasemi-Esmailabad, S.; Ghasemi, N. Frequency of TNFR1 36 A/G gene polymorphism in azoospermic infertile men: A case-control study. Int. J. Reprod. Biomed. 2017, 15, 521-526. [CrossRef]

184. Moghbelinejad, S.; Najafipour, R.; Momeni, A. Association of rs1057035polymorphism in microRNA biogenesis pathway gene (DICER1) with azoospermia among Iranian population. Genes Genom. 2018, 40, 17-24. [CrossRef]

185. Sato, Y.; Hasegawa, C.; Tajima, A.; Nozawa, S.; Yoshiike, M.; Koh, E.; Kanaya, J.; Namiki, M.; Matsumiya, K.; Tsujimura, A.; et al. Association of TUSC1 and DPF3 gene polymorphisms with male infertility. J. Assist. Reprod. Genet. 2018, 35, 257-263. [CrossRef]

186. Teimouri, M.; Najaran, H.; Hosseinzadeh, A.; Mazoochi, T. Association between two common transitions of H2BFWT gene and male infertility: A case-control, meta, and structural analysis. Andrology 2018, 6, 306-316. [CrossRef]

187. Zamani-Badi, T.; Karimian, M.; Azami Tameh, A.; Nikzad, H. IL-1a C376A Transversion Variant and Risk of Idiopathic Male Infertility in Iranian Men: A Genetic Association Study. Int. J. Fertil. Steril. 2018, 12, $229-234$.

188. Zamani-Badi, T.; Nikzad, H.; Karimian, M. IL-1RA VNTR and IL-1alpha 4845G>T polymorphisms and risk of idiopathic male infertility in Iranian men: A case-control study and an in silico analysis. Andrologia 2018, 50, e13081. [CrossRef]

189. Yu, C.H.; Xie, T.; Zhang, R.P.; A, Z.-C. Association of the common SNPs in RNF212, STAG3 and RFX2 gene with male infertility with azoospermia in Chinese population. Eur. J. Obstet. Gynecol. Reprod. Biol. 2018, 221, 109-112. [CrossRef]

190. Singh, V.; Bansal, S.K.; Sudhakar, D.V.S.; Neelabh Chakraborty, A.; Trivedi, S.; et al. SNPs in ERCC1, ERCC2, and XRCC1 genes of the DNA repair pathway and risk of male infertility in the Asian populations: Association study, meta-analysis, and trial sequential analysis. J. Assist. Reprod. Genet. 2019, 36, 79-90. [CrossRef] 
191. Busch, A.S.; Tuttelmann, F.; Cremers, J.F.; Schubert, M.; Nordhoff, V.; Schuring, A.N.; Zitzmann, M.; Gromoll, J.; Kliesch, S. FSHB -211 G>T Polymorphism as Predictor for TESE Success in Patients with Unexplained Azoospermia. J. Clin. Endocrinol. Metab. 2019, 104, 2315-2324. [CrossRef] [PubMed]

192. Zhao, X.; Mu, C.; Ma, J.; Dai, X.; Jiao, H. The association of four SNPs in DNA mismatch repair genes with idiopathic male infertility in northwest China. Int. J. Immunogenet. 2019, 46, 451-458. [CrossRef]

193. Huang, M.; Zhu, M.; Jiang, T.; Wang, Y.; Wang, C.; Jin, G.; Guo, X.; Sha, J.; Dai, J.; Wang, X.; et al. Fine mapping the MHC region identified $\mathrm{rs} 4997052$ as a new variant associated with nonobstructive azoospermia in Han Chinese males. Fertil. Steril. 2019, 111, 61-68. [CrossRef] [PubMed]

194. Nam, Y.; Kang, K.M.; Sung, S.R.; Park, J.E.; Shin, Y.J.; Song, S.H.; Seo, J.T.; Yoon, T.K.; Shim, S.H. The association of stromal antigen 3 (STAG3) sequence variations with spermatogenic impairment in the male Korean population. Asian J. Androl. 2020, 22, 106-111. [PubMed]

195. Pennisi, E. Breakthrough of the year. Human genetic variation. Science 2007, 318, 1842-1843. [CrossRef]

196. Hofker, M.H.; Fu, J.; Wijmenga, C. The genome revolution and its role in understanding complex diseases. Biochim. Biophys. Acta 2014, 1842, 1889-1895. [CrossRef]

197. Aston, K.I.; Carrell, D.T. Genome-wide study of single-nucleotide polymorphisms associated with azoospermia and severe oligozoospermia. J. Androl. 2009, 30, 711-725. [CrossRef]

198. Johnson, R.C.; Nelson, G.W.; Troyer, J.L.; Lautenberger, J.A.; Kessing, B.D.; Winkler, C.A.; et al. Accounting for multiple comparisons in a genome-wide association study (GWAS). BMC Genom. 2010, 11, 724. [CrossRef]

199. Pe'er, I.; Yelensky, R.; Altshuler, D.; Daly, M.J. Estimation of the multiple testing burden for genomewide association studies of nearly all common variants. Genet. Epidemiol. 2008, 32, 381-385. [CrossRef]

200. Fadista, J.; Manning, A.K.; Florez, J.C.; Groop, L. The (in)famous GWAS P-value threshold revisited and updated for low-frequency variants. Eur. J. Hum. Genet. 2016, 24, 1202-1205. [CrossRef]

201. Xu, M.; Qin, Y.; Qu, J.; Lu, C.; Wang, Y.; Wu, W.; Song, L.; Wang, S.; Chen, F.; Shen, H.; et al. Evaluation of five candidate genes from GWAS for association with oligozoospermia in a Han Chinese population. PLoS ONE 2013, 8, e80374. [CrossRef] [PubMed]

202. Sato, Y.; Jinam, T.; Iwamoto, T.; Yamauchi, A.; Imoto, I.; Inoue, I.; Tajima, A. Replication study and meta-analysis of human nonobstructive azoospermia in Japanese populations. Biol. Reprod. 2013, 88, 87. [CrossRef] [PubMed]

203. Gu, X.; Li, H.; Chen, X.; Zhang, X.; Mei, F.; Jia, M.; Xiong, C. PEX10, SIRPA-SIRPG, and SOX5 gene polymorphisms are strongly associated with nonobstructive azoospermia susceptibility. J. Assist. Reprod. Genet. 2019, 36, 759-768. [CrossRef]

204. Zhang, Y.; Qian, J.; Wu, M.; Liu, M.; Zhang, K.; Lin, Y.; Guo, X.; Zhou, Z.; Hu, Z.; Sha, J. A susceptibility locus rs7099208 is associated with non-obstructive azoospermia via reduction in the expression of FAM160B1. J. Biomed. Res. 2015, 29, 491-500.

205. Zou, S.; Song, P.; Meng, H.; Chen, T.; Chen, J.; Wen, Z.; Li, Z.; Shi, Y.; Hu, H. Association and meta-analysis of HLA and non-obstructive azoospermia in the Han Chinese population. Andrologia 2017, 49. [CrossRef]

206. Perez, C.V.; Theas, M.S.; Jacobo, P.V.; Jarazo-Dietrich, S.; Guazzone, V.A.; Lustig, L. Dual role of immune cells in the testis: Protective or pathogenic for germ cells? Spermatogenesis 2013, 3, e23870. [CrossRef]

207. Jinam, T.A.; Nakaoka, H.; Hosomichi, K.; Mitsunaga, S.; Okada, H.; Tanaka, A.; Tanaka, K.; Inoue, I. HLA-DPB1*04:01 allele is associated with non-obstructive azoospermia in Japanese patients. Hum. Genet. 2013, 132, 1405-1411. [CrossRef]

208. Kosova, G.; Scott, N.M.; Niederberger, C.; Prins, G.S.; Ober, C. Genome-wide association study identifies candidate genes for male fertility traits in humans. Am. J. Hum. Genet. 2012, 90, 950-961. [CrossRef]

209. Ni, B.; Lin, Y.; Sun, L.; Zhu, M.; Li, Z.; Wang, H.; Yu, J.; Guo, X.; Zuo, X.; Dong, J.; et al. Low-frequency germline variants across 6 p22.2-6p21.33 are associated with non-obstructive azoospermia in Han Chinese men. Hum. Mol. Genet. 2015, 24, 5628-5636.

210. Tuttelmann, F.; Simoni, M.; Kliesch, S.; Ledig, S.; Dworniczak, B.; Wieacker, P.; Ropke, A. Copy number variants in patients with severe oligozoospermia and Sertoli-cell-only syndrome. PLoS ONE 2011, 6, e19426. [CrossRef]

211. Krausz, C.; Giachini, C.; Lo Giacco, D.; Daguin, F.; Chianese, C.; Ars, E.; Ruiz-Castane, E.; Forti, G.; Rossi, E. High resolution $X$ chromosome-specific array-CGH detects new CNVs in infertile males. PLoS ONE 2012, 7, e44887. [CrossRef] 
212. Stouffs, K.; Vandermaelen, D.; Massart, A.; Menten, B.; Vergult, S.; Tournaye, H.; Lissens, W. Array comparative genomic hybridization in male infertility. Hum. Reprod. 2012, 27, 921-929. [CrossRef] [PubMed]

213. Lo Giacco, D.; Chianese, C.; Ars, E.; Ruiz-Castane, E.; Forti, G.; Krausz, C. Recurrent X chromosome-linked deletions: Discovery of new genetic factors in male infertility. J. Med. Genet. 2014, 51, 340-344. [CrossRef] [PubMed]

214. Wu, W.; Qin, Y.; Li, Z.; Dong, J.; Dai, J.; Lu, C.; Guo, X.; Zhao, Y.; Zhu, Y.; Zhang, W.; et al. Genome-wide microRNA expression profiling in idiopathic non-obstructive azoospermia: Significant up-regulation of miR-141, miR-429 and miR-7-1-3p. Hum. Reprod. 2013, 28, 1827-1836. [CrossRef] [PubMed]

215. Jiang, T.; Wang, Y.; Zhu, M.; Huang, M.; Jin, G.; Guo, X.; Sha, J.; Dai, J.; Hu, Z. Transcriptome-wide association study revealed two novel genes associated with nonobstructive azoospermia in a Chinese population. Fertil. Steril. 2017, 108, 1056-1062.e1054. [CrossRef] [PubMed]

216. Ferfouri, F.; Boitrelle, F.; Ghout, I.; Albert, M.; Molina Gomes, D.; Wainer, R.; Bailly, M.; Selva, J.; Vialard, F. A genome-wide DNA methylation study in azoospermia. Andrology 2013, 1, 815-821. [CrossRef] [PubMed]

217. Han, F.; Jiang, X.; Li, Z.M.; Zhuang, X.; Zhang, X.; Ouyang, W.M.; Liu, W.B.; Mao, C.Y.; Chen, Q.; Huang, C.S.; et al. Epigenetic Inactivation of SOX30 Is Associated with Male Infertility and Offers a Therapy Target for Non-obstructive Azoospermia. Mol. Ther. Nucleic Acids 2019, 19, 72-83. [CrossRef]

218. Cannarella, R.; Condorelli, R.A.; Duca, Y.; La Vignera, S.; Calogero, A.E. New insights into the genetics of spermatogenic failure: A review of the literature. Hum. Genet. 2019, 138, 125-140. [CrossRef]

219. Chalmel, F.; Lardenois, A.; Evrard, B.; Mathieu, R.; Feig, C.; Demougin, P.; Gattiker, A.; Schulze, W.; Jegou, B.; Kirchhoff, C.; et al. Global human tissue profiling and protein network analysis reveals distinct levels of transcriptional germline-specificity and identifies target genes for male infertility. Hum. Reprod. 2012, 27, 3233-3248. [CrossRef]

220. Yan, W. Male infertility caused by spermiogenic defects: Lessons from gene knockouts. Mol. Cell. Endocrinol. 2009, 306, 24-32. [CrossRef]

221. Guo, J.; Grow, E.J.; Mlcochova, H.; Maher, G.J.; Lindskog, C.; Nie, X.; Guo, Y.; Takei, Y.; Yun, J.; Cai, L.; et al. The adult human testis transcriptional cell atlas. Cell Res. 2018, 28, 1141-1157. [CrossRef]

222. Mitchell, M.J.; Metzler-Guillemain, C.; Toure, A.; Coutton, C.; Arnoult, C.; Ray, P.F. Single gene defects leading to sperm quantitative anomalies. Clin. Genet. 2017, 91, 208-216. [CrossRef]

223. Ghieh, F.; Mitchell, V.; Mandon-Pepin, B.; Vialard, F. Genetic defects in human azoospermia. Basic Clin. Androl. 2019, 29, 4. [CrossRef] [PubMed]

224. Asero, P.; Calogero, A.E.; Condorelli, R.A.; Mongioi, L.; Vicari, E.; Lanzafame, F.; et al. Relevance of genetic investigation in male infertility. J. Endocrinol. Investig. 2014, 37, 415-427. [CrossRef] [PubMed]

225. Punab, M.; Poolamets, O.; Paju, P.; Vihljajev, V.; Pomm, K.; Ladva, R.; et al. Causes of male infertility: A 9-year prospective monocentre study on 1737 patients with reduced total sperm counts. Hum. Reprod. 2017, 32, 18-31. [CrossRef] [PubMed]

(C) 2020 by the authors. Licensee MDPI, Basel, Switzerland. This article is an open access article distributed under the terms and conditions of the Creative Commons Attribution (CC BY) license (http://creativecommons.org/licenses/by/4.0/). 